\title{
Layer III Neurons Control Synchronized Waves in the Immature Cerebral Cortex
}

\author{
Shigehiro Namiki, ${ }^{1,2}$ Hiroaki Norimoto, ${ }^{1 \star}$ Chiaki Kobayashi, ${ }^{1 \star}$ Kei Nakatani, ${ }^{2}$ Norio Matsuki, ${ }^{1}$ and Yuji Ikegaya ${ }^{1}$ \\ ${ }^{1}$ Laboratory of Chemical Pharmacology, Graduate School of Pharmaceutical Sciences, The University of Tokyo, Tokyo 113-0033, Japan, and ${ }^{2}$ Graduate \\ School of Life and Environmental Sciences, University of Tsukuba, Ibaraki 305-8572, Japan
}

Correlated spiking activity prevails in immature cortical networks and is believed to contribute to neuronal circuit maturation; however, its spatiotemporal organization is not fully understood. Using wide-field calcium imaging from acute whole-brain slices of rat pups on postnatal days 1-6, we found that correlated spikes were initiated in the anterior part of the lateral entorhinal cortex and propagated anteriorly to the frontal cortex and posteriorly to the medial entorhinal cortex, forming traveling waves that engaged almost the entire cortex. The waves were blocked by ionotropic glutamatergic receptor antagonists but not by GABAergic receptor antagonists. During wave events, glutamatergic and GABAergic synaptic inputs were balanced and induced UP state-like depolarization. Magnified monitoring with cellular resolution revealed that the layer III neurons were first activated when the waves were initiated. Consistent with this finding, layer III contained a larger number of neurons that were autonomously active, even under a blockade of synaptic transmission. During wave propagation, the layer III neurons constituted a leading front of the wave. The waves did not enter the parasubiculum; however, in some cases, they were reflected at the parasubicular border and propagated back in the opposite direction. During this reflection process, the layer III neurons in the medial entorhinal cortex maintained persistent activity. Thus, our data emphasize the role of layer III in early network behaviors and provide insight into the circuit mechanisms through which cerebral cortical networks maturate.

\section{Introduction}

Propagating waves of neuronal activity are crucial in computation and communication between neuronal networks (Ermentrout and Kleinfeld, 2001; Lubenov and Siapas, 2008; Wu et al., 2008) and have been described in various nervous systems, including sensory systems (Kleinfeld et al., 1994), the neocortex (Massimini et al., 2004; Xu et al., 2007), and the hippocampus (Lubenov and Siapas, 2009). In particular, wave activity prevails in immature neural networks of model animals (Katz and Shatz, 1996; O’Donovan, 1999; Peinado, 2000; Ben-Ari, 2001; Khazipov et al., 2001; Zhang and Poo, 2001; Calderon et al., 2005; Bolea et al., 2006; Khazipov and Luhmann, 2006; Allène et al., 2008; Golshani et al., 2009; Seki et al., 2012), and its phenomenological characteristics resemble those observed in the developing human brain (Colonnese et al., 2010). Early network waves are believed to be essential in neuronal differentiation, synaptogenesis, and circuit wiring (Moody and Bosma, 2005; Spitzer, 2006; Blanken-

Received May 25, 2012; revised Sept. 10, 2012; accepted 0ct. 24, 2012.

Author contributions: S.N., K.N., N.M., and Y.I. designed research; S.N., H.N., and C.K. performed research; S.N., H.N., C.K., and Y.I. analyzed data; S.N. and Y.I. wrote the paper.

This work was partly supported by grants-in-aid for science research (№. 22115003) from MEXT (Japan's Ministry of Education, Culture, Sports, Science and Technology) and by the funding program for Next Generation WorldLeading Researchers (LSO23).

*H.N. and C.K. contributed equally to this work.

Correspondence should be addressed to Yuji Ikegaya, Laboratory of Chemical Pharmacology, Graduate School of Pharmaceutical Sciences, The University of Tokyo, Tokyo 113-0033, Japan. E-mail: ikegaya@mol.f.u-tokyo.ac.jp.

S.N.'s present address: Research Center for Advanced Science and Technology, The University of Tokyo, Tokyo 153-8904, Japan.

DOI:10.1523/JNEUROSCI.2522-12.2013

Copyright $\odot 2013$ the authors $\quad 0270-6474 / 13 / 330987-15 \$ 15.00 / 0$ ship and Feller, 2010), and abnormal wave patterns during development are subsequently related to neurological disorders (Le Van Quyen et al., 2006; Allène et al., 2008; Seki et al., 2012).

Cortical waves are diverse in their spatiotemporal patterns (Arieli et al., 1996; Benucci et al., 2007; Han et al., 2008; Huang et al., 2010). A prominent example is the reflection of waves at the border between different cortical areas (Xu et al., 2007). Bidirectional waves are also found in the adult brain in vitro (Kim et al., 1995; Sanchez-Vives and McCormick, 2000) and in vivo (Bao and Wu, 2003; Rubino et al., 2006; Luczak et al., 2007). Waves with different directions may carry different information content (Roland et al., 2006; Rubino et al., 2006; Takahashi et al., 2011a).

Previous studies have focused mainly on the macroscopic behavior of waves, and little is known about how the waves emerge, propagate, terminate, or reflect at the microcircuit level. This gap in the literature is largely due to the lack of an appropriate experimental method; that is, macroscopic imaging lacks cellular resolution, and higher resolution imaging makes it extremely difficult to identify the generation or termination site of waves. To overcome this problem, we used both macroscopic and microscopic imaging techniques in combination with electrophysiological recordings.

\section{Materials and Methods}

Animal experiment ethics. All experiments were performed with the approval of the animal experiment ethics committee at the University of Tokyo (approval number: 19-35) and in accordance with the University of Tokyo guidelines for the care and use of laboratory animals.

Materials. Oregon Green BAPTA-1 AM (OGB1AM), NeuroTrace 530/615, and Pluronic F-127 were obtained from Invitrogen. D-2- 


\section{A}

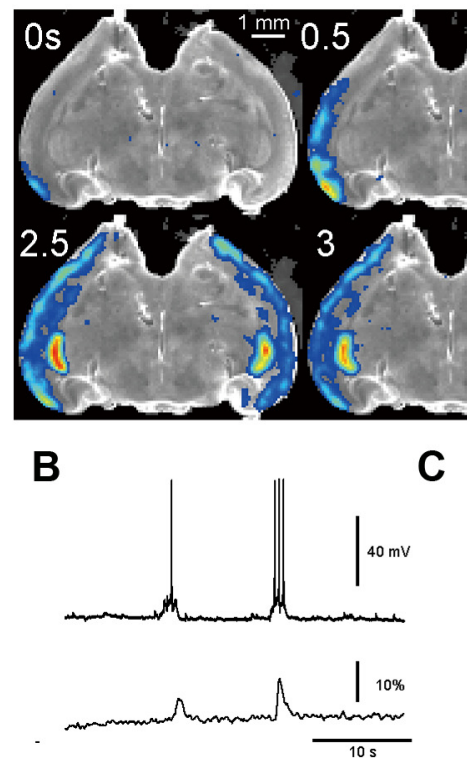

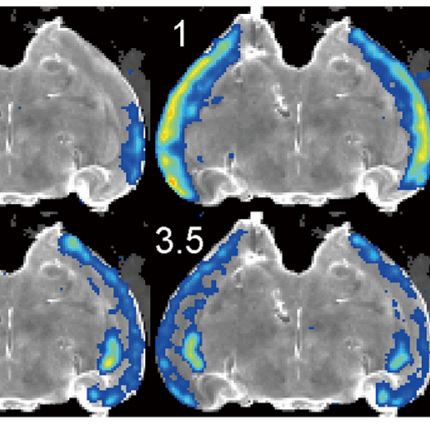
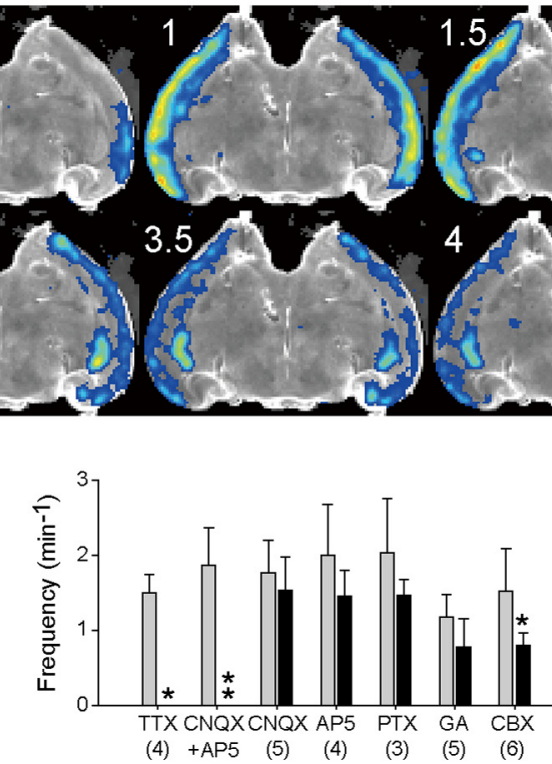

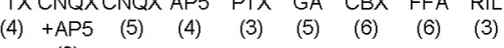

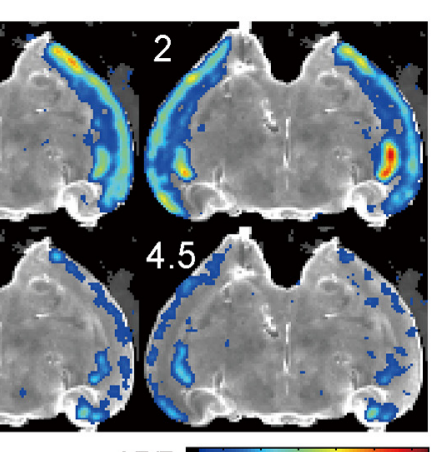

$\Delta F / F$

\section{西}

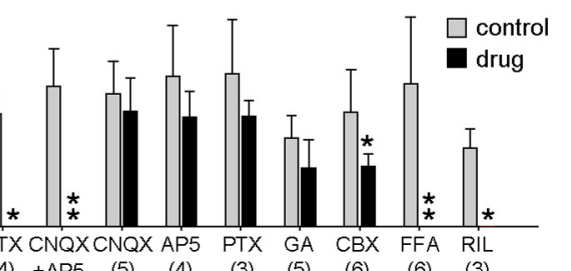

(9)

Figure 1. Large-scale cortical synchronized waves in acute brain slices prepared from immature rats. $\boldsymbol{A}$, Low-magnification time-lapse calcium imaging of a synchronized wave in a horizontal whole-brain slice. A posterior region of the cerebral cortex is the source of the synchronized wave. $\boldsymbol{B}$, Simultaneous whole-cell patch-clamp recording (top) and calcium imaging (bottom) from the same cell, revealing that individual calcium activities reflected action potentials. C, Frequencies of synchronized waves before and after bath application of inhibitors [i.e., $1 \mu \mathrm{M}$ TTX, $20 \mu \mathrm{m}$ CNQX plus $50 \mu \mathrm{m}$ AP5 (CNQX + AP5), $20 \mu \mathrm{m}$ CNQX, $50 \mu \mathrm{m}$ AP5, $100 \mu \mathrm{m}$ picrotoxin (PTX), $100 \mu \mathrm{m}$ 18 $\beta$-glycyrrhetinic acid (GA), $100 \mu \mathrm{m}$ carbenoxolone (CBX), $100 \mu \mathrm{m}$ flufenamic acid (FFA, CAN channel blocker), and $30 \mu \mathrm{m}$ riluzole ( $\mathrm{pNa}$ channel blocker)]. The numbers in parentheses indicate the numbers of slices tested. Data are means $\pm \mathrm{SDs} .{ }^{*} p<0.05,{ }^{* *} p<0.001$ versus control, Mann-Whitney $U$ test.

Amino-5-phosphonopentanoic acid (AP5), carbenoxolone, 6-cyano7-nitroquinoxaline-2,3-dione (CNQX), Cremophor EL, flufenamic acid, $18 \beta$-glycyrrhetinic acid, picrotoxin, riluzole, and saclofen were obtained from Sigma-Aldrich. Stock solutions were stored at $-20^{\circ} \mathrm{C}$ and diluted immediately before use.

Slice preparations. Postnatal 1-6-d-old (P1-P6) male rats (Japan SLC) were deeply anesthetized with ether and ice. The brain was quickly isolated $(<30 \mathrm{~s})$ and immersed in ice-cold modified artificial CSF (aCSF) consisting of (in $\mathrm{mM}$ ) the following: $27 \mathrm{NaHCO}_{3}, 1.4 \mathrm{NaH}_{2} \mathrm{PO}_{4}, 2.5 \mathrm{KCl}$, 7.0 $\mathrm{MgSO}_{4}, 1.0 \mathrm{CaCl}_{2}, 222.1$ sucrose, and 0.5 ascorbic acid. These salts were all obtained from Wako Chemicals. aCSF was continuously bubbled with $95 \% \mathrm{O}_{2}$ and $5 \% \mathrm{CO}_{2}$. The leptomeninx was carefully removed by two pairs of sharp tweezers, a process critical for making slice preparations flat enough for wide-field imaging. Horizontal slices $400 \mu \mathrm{m}$ thick were prepared using a vibratome (Vibratome 3000, Vibratome). Slices at depths of $400-1600 \mu \mathrm{m}$ from the ventral surface of the brain were used for experiments. The same surface of each slice was kept upright during the incubation and experiments. The slices were maintained for $30 \mathrm{~min}$ at room temperature in aCSF, consisting of (in $\mathrm{mm}$ ) the following: $127 \mathrm{NaCl}, 26 \mathrm{NaHCO}_{3}, 1.5 \mathrm{KCl}, 1.24 \mathrm{KH}_{2} \mathrm{PO}_{4}, 1.4 \mathrm{MgSO}_{4}, 2.0$ $\mathrm{CaCl}_{2}$, and 10 glucose. For P5-P6 slices, the concentration of $\mathrm{CaCl}_{2}$ in aCSF was lowered to $1.0 \mathrm{~mm}$ because the extracellular calcium ion concentration in vivo reduces to this level after P5 (Math and Davrainville, 1979). To examine the reproducibility of the wave dynamics, we also used aCSF consisting of (in $\mathrm{mm}$ ) the following: $124 \mathrm{NaCl}, 26 \mathrm{NaHCO}_{3}, 3.5$ $\mathrm{KCl}, 1 \mathrm{MgCl}_{2}, 1.2 \mathrm{CaCl}_{2}, 10$ glucose, modified from aCSF reported in Sanchez-Vives and McCormick (2000). Cortical waves were consistently observed in P1-P6 slices and did not show age-dependent differences in the parameters used in this work. Thus, all of the data were pooled for quantitative analysis, although only P1-P3 slices were used for the wholebrain slice imaging so that they could be viewed under the limited microscopic field (Figs. 1A, 2A).

\section{Calcium imaging}

The slices were transferred into a $35 \mathrm{~mm}$ dish filled with $4 \mathrm{ml}$ of the recording aCSF, and $5 \mu \mathrm{l}$ of dye solution was directly puffed onto the slice surface (Ikegaya et al., 2005). The dye solution consisted of $0.07 \%$
OGB1AM, 1.4\% Pluronic F-127, and 0.7\% Cremophor EL in DMSO (Takahashi et al., 2011b). The slices were incubated for $30 \mathrm{~min}$ at room temperature in a custom-made chamber. After washing, the slices were maintained in dye-free aCSF at room temperature for $>30 \mathrm{~min}$. A slice was transferred into an imaging chamber perfused with $34-36^{\circ} \mathrm{C}$ aCSF at $2-3 \mathrm{ml} / \mathrm{min}$. After a stabilization period of $15 \mathrm{~min}$, imaging of spontaneous or evoked calcium signals was begun. Electrical stimulation (pulse duration, $50 \mu \mathrm{s}$; intensity, 5-80 $\mu \mathrm{A}$ ) was performed using bipolar tungsten electrodes. Images were captured at 10-50 frames/s with a Nipkow disk confocal unit (CSU22 or CSUX1, Yokogawa Electric), a cooled CCD camera (iXon DV887 or DV897, Andor Technology), an upright microscope (Eclipse FN1, Nikon), objectives $(1 \times, 0.04$ numerical aperture, Plan UW; 4×, 0.13 numerical aperture, Plan Fluor; 16×, 0.80 numerical aperture, CFI75 LWD 16XW; Nikon), and image acquisition software (Solis, Andor Technology). OGB1 was excited at $488 \mathrm{~nm}$ with an argon-krypton laser (10-20 mW, 641-YB-A01, Melles Griot) and visualized through a $507 \mathrm{~nm}$ longpass emission filter. For local application of GABA, $200 \mu \mathrm{M}$ GABA was loaded in glass pipettes and pressure-applied to the slice surface (Sasaki et al., 2011). In this experiment, $200 \mu \mathrm{M}$ saclofen was also added to intrapipette aCSF to prevent $\mathrm{GABA}_{\mathrm{B}}$ receptor activation, which may induce calcium mobilization from somatic endoplasmic reticulum.

Patch-clamp recording. Whole-cell patch-clamp recordings were performed with glass pipettes filled with solution containing (in $\mathrm{mM}$ ) the following: $130 \mathrm{~K}$-gluconate, $9 \mathrm{KCl}, 0.1 \mathrm{CaCl}_{2}, 10 \mathrm{HEPES}$, and $1 \mathrm{EGTA} ;$ Mg-ATP, $0.4 \mathrm{Na}_{2} \mathrm{GTP}$, pH 7.2, for voltage clamp; and $135 \mathrm{~K}$-gluconate, 4 $\mathrm{KCl}, 10$ HEPES, 10 phosphocreatine, $4 \mathrm{Mg}$-ATP, $0.3 \mathrm{Na}_{2} \mathrm{GTP}, \mathrm{pH} 7.2$, for current clamp. Filament borosilicate glass capillaries were used to prepared electrodes (5-8 M $\Omega$ ). Capillaries were pulled with a puller (P-97, Sutter Instruments). Recordings were performed using Multiclamp 700B (Molecular Devices). Pipette seal resistances were typically $>1 \mathrm{G} \Omega$, and pipette capacitive transients were minimized before breakthrough. Glutamatergic and GABAergic postsynaptic currents (PSCs) were predominated at clamped voltages of 0 and $-73 \mathrm{mV}$, respectively, in P5-P6 slices. Signals were low-pass filtered at $1 \mathrm{kHz}$, digitized at $10 \mathrm{kHz}$, and analyzed with pCLAMP 10 software (Molecular Devices).

Local field potential recording. Recordings were conducted in a submersion-type recording chamber (volume, $1.8 \mathrm{ml}$ ) perfused with 


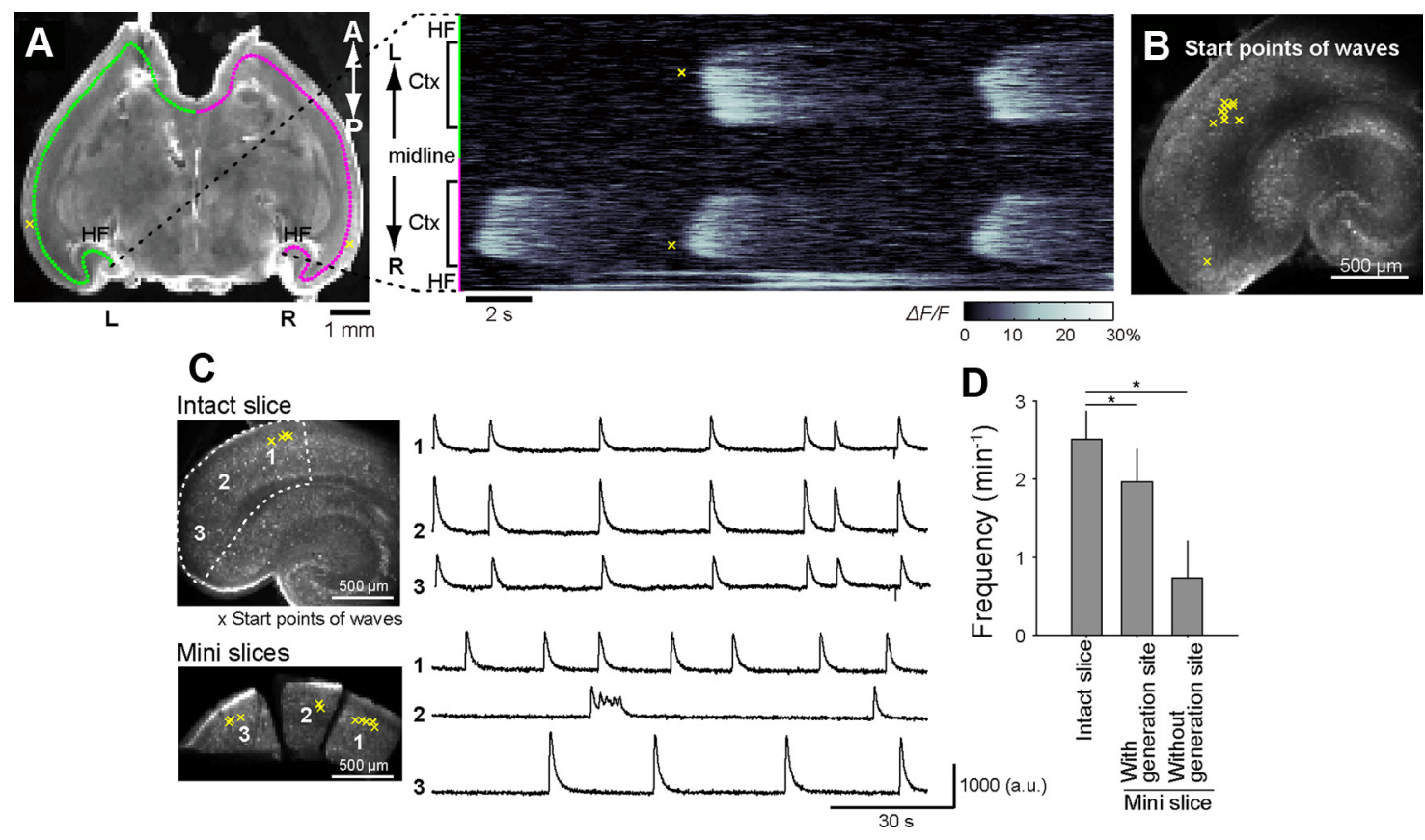

Figure 2. Wave initiation in LEC. A, Representative line-scan plot of the calcium signal across bilateral cerebral cortices. The calcium signal (right) measured along the red line shown in the left image indicates the LEC as an origin of synchronized waves. Yellow asterisks indicate the initiation sites (the mass centers of the earliest activated areas) of the second wave in the left plot. A, anterior; Ctx, cortex; HF, hippocampal formation; L, left, P, posterior. R, right. B, The initiation sites of individual waves are indicated by yellow asterisks, many of which were located in layer III of the LEC. C, Comparison of synchronized waves in three zones (1-3) of the EC before (top) and after (bottom) surgical dissection. 1, anterior LEC; 2, border area between the LEC and the MEC; 3 , posterior MEC. The right traces indicate the changes in the fluorescence intensity of the corresponding zones. Every part of the cortex was capable of generating spontaneous activity. $\boldsymbol{D}$, Wave frequency in intact slice and minislices. Although the wave frequency was lower in the minislices, the minislices that contained the original site of wave initiation (i.e., zone 1) exhibited waves more frequently than other minislices. Data are means \pm SDs of five slices. ${ }^{*} p<0.001$, Mann-Whitney's $U$ test.

aCSF (saturated with $95 \% \mathrm{O}_{2}$ and $5 \% \mathrm{CO}_{2}$ at $37^{\circ} \mathrm{C}$ ) at $\sim 10 \mathrm{ml} / \mathrm{min}$. Field potentials were recorded from lateral entorhinal cortex (LEC) layer III using borosilicate glass capillaries $(0.5-1.2 \mathrm{M} \Omega$ ) filled with aCSF. Signals were low-pass filtered at $1 \mathrm{kHz}$, amplified by MultiClamp 700B, digitized at $20 \mathrm{kHz}$ by pCLAMP 10.2 (Molecular Devices) software, and offline analyzed using custom-made Matlab routines (MathWorks).

Data analysis. For wide-field imaging, videos were taken at $10-20 \mathrm{~Hz}$ and spatially filtered with a $3 \times 3$-pixel Gaussian kernel. The images were further smoothed through a $100 \mathrm{~ms}$ window hamming filter. Wide-field images were analyzed using custom-made Matlab routines with the image processing toolbox. Time periods during which the slice did not show activity were manually selected and used for the baseline fluorescence intensity. For each pixel, the fluorescence change was calculated as $\left(F_{t}-\right.$ $\left.F_{0}\right) / F_{0}$, where $F_{t}$ is the fluorescence intensity at time $t$ and $F_{0}$ is the average signal intensity during the baseline period. For the pseudocolored presentation of calcium activity, pixels that showed fluorescence changes $>2 \times$ SD of $F_{0}$ were shown in a heat map and were merged with the raw image. The three-dimensional $x y t$ plots were illustrated using the image processing software Avizo 6.3 (Visage Imaging). For imaging at singlecell resolution, videos were taken at $50 \mathrm{~Hz}$ and the contours of the cells were automatically detected using the Matlab function "bwlabel." False contour detection was manually rejected (Ikegaya et al., 2004). Time series of the OGB1 fluorescence intensity were measured in individual cells. For each cell, the fluorescence change was calculated as $\left(F_{t}-F_{0}\right) / F_{0}$. Spike-triggered calcium increases were determined with a customwritten routine in Matlab (Takahashi et al., 2010, 2012). Non-neuronal cells were discarded based on the criteria used in our previous reports (Sasaki et al., 2007, 2011). To identify the locus of the wave initiation, we determined the mask image of the $>5 \%$ fluorescence activity at every frame, and the mass center of the mask at the first frame in which the wave appeared was defined as the wave initiation zone. Two criteria were used to define autonomously active cells: (1) they showed spontaneous activity in the presence of $20 \mu \mathrm{M}$ CNQX, $100 \mu \mathrm{M} \mathrm{AP5}$, and $100 \mu \mathrm{M}$ picrotoxin; and (2) their activity, when it lasted longer than $1 \mathrm{~s}$, occurred at a frequency of $>1$ event per $10 \mathrm{~min}$. Cortical layers were determined based on the cell density and the soma sizes of neurons. The entorhinal cortex was divided into the LEC and medial entorhinal cortex (MEC), based on the appearance of layer II and the thickness of the lamina dissecans.

Statistics and data representation. Statistical tests and classifications were performed using the Matlab statistics toolbox. The data are summarized as the mean $\pm \mathrm{SD}$.

\section{Results}

\section{Spatiotemporal patterns of synchronized waves}

To examine the large-scale organization of early network activity in the immature cerebral cortex, we used a low-magnification $(1 \times)$ objective so that the microscopic field fully covered an acute horizontal slice of the rat whole brain (Fig. 1A). OGB1-loaded slices intermittently exhibited spontaneous calcium elevations synchronized throughout the cerebral cortex. This spontaneous activity was observed in all slices prepared from P1-P6 rats, and the event frequencies were $2.4 \pm 2.1$ per minute (mean \pm SD of 75 slices). These calcium events accompanied action potentials and UP state-like persistent depolarization of neurons (Fig. $1 B$; see also Fig. $11 B$ ) and were inhibited by bath application of $1 \mu \mathrm{M}$ TTX (Fig. $1 C ; p=1.2 \times 10^{-3}, t_{3}=12.3$, paired $t$ test, $n=4$ slices).

We examined the spatiotemporal dynamics of the spontaneous activity in wide-field videos captured at $20 \mathrm{~Hz}$ and found that these calcium events were traveling waves. The propagation speed was $\sim 1-7 \mathrm{~mm} / \mathrm{s}$ and varied depending on the cortical region and the wave direction (see Fig. 8). The main locus where the calcium activity was initiated was a posterior region of the brain (Fig. 1A). This region corresponds to the most anterior part of the LEC, which is close to the perirhinal cortex. Once initiated, the activity bifurcated in the anterior and posterior directions, 
propagated along the tangential axis of the cortex, and eventually spread over almost the entire cortex (Figs. 1A, 2A). The waves sometimes co-occurred in both hemispheres with a small time delay of $<0.5 \mathrm{~s}$; note that the wave shown in Figure $1 A$ arose from the left LEC. We observed the bihemispheric waves in four of the total 12 slices. In one of the four slices, we dissected both hemispheres at the midline by surgically cutting the ventral $75 \%$ part (a region that was posterior to the third ventricle), but the bilateral waves were preserved in this partially incised slice, suggesting that the anterior commissure mediates interhemispheric synchronization. They were occasionally propagated to the hippocampus, the amygdala, and the subiculum (Figs. $1 A, 2 A$ ); however, we failed to find waves occurring in the parasubiculum, the thalamus, or the pons.

\section{Pharmacological characterization synchronized waves}

To examine the mechanisms underlying these traveling waves, we conducted a series of pharmacological experiments (Fig. 1C). Bath application of either $20 \mu \mathrm{M}$ CNQX, a non-NMDA receptor antagonist, or $100 \mu \mathrm{M}$ AP5, an NMDA receptor antagonist, alone had no effect (CNQX: $p=0.51, t_{4}=0.719, n=5$ slices; AP5: $p=$ $0.075, t_{3}=2.67$, paired $t$ test, $n=4$ slices), but the mixture of both antagonists blocked the waves $\left(p=3.5 \times 10^{-6}, t_{8}=11.3, n=9\right.$ slices). Similar results have been reported in the cortex in vivo (Minlebaev et al., 2009) and in vitro (Sheroziya et al., 2009), indicating that cortical waves are driven by chemical synaptic transmission. Application of $100 \mu \mathrm{M}$ picrotoxin, a $\mathrm{GABA}_{\mathrm{A}}$ receptor antagonist, did not inhibit the waves $\left(p=0.25, t_{2}=1.61, n=3\right.$ slices). These data suggest that glutamatergic synaptic transmission plays a pivotal role in generating the waves and that our waves are distinct from GABA-mediated giant depolarizing potentials (Allène et al., 2008).

Application of $100 \mu \mathrm{M}$ carbenoxolone, a broad inhibitor of gap junction, slightly reduced the wave event frequency $(p=$ $0.031, t_{5}=2.99, n=6$ slices), whereas $100 \mu \mathrm{M} 18 \beta$-glycyrrhetinic acid, a more specific inhibitor of gap junction, did not significantly reduce the wave frequency $\left(p=0.13, t_{4}=2.52, n=5\right.$ slices). Thus, the waves we observed here are different from cortical synchronous plateau assemblies (Crépel et al., 2007) or gap junction-mediated network oscillations (Sun and Luhmann, 2007).

The waves were also inhibited by $100 \mu \mathrm{M}$ flufenamic acid, a blocker of calcium-dependent nonselective cation (CAN) currents, which are known to contribute to persistent spiking activity in the adult entorhinal cortex (EC) (Egorov et al., 2002; Fransén et al., 2006) $\left(p=8.8 \times 10^{-3}, t_{5}=4.78, n=6\right.$ slices $)$, and by 30 $\mu \mathrm{M}$ riluzole, a blocker of persistent sodium ( $\mathrm{pNa}$ ) currents $(p=$ $0.019, t_{2}=7.00, n=3$ slices). Flufenamic acid and riluzole have been reported to inhibit prolonged bursting activity in layer III of the developing EC (Sheroziya et al., 2009). CAN currents contribute to persistent firing activity even in the adult EC (Egorov et al., 2002; Fransén et al., 2006; Tahvildari et al., 2007). In adulthood, cholinergic innervations from the medial septum are required for this persistent firing activity (Egorov et al., 2002), whereas in the developmental stage that we focused on, cholinergic fibers are still lacking (Reboreda et al., 2007). Recently, Yoshida and Alonso (2007) reported acetylcholine-independent persistent firing in layer III of the EC, indicating that NMDA receptor activity alone is sufficient to maintain the persistent firing activity. Thus, calcium influx through NMDA receptors may activate CAN currents and thereby cause persistent firing activity in the developing EC. pNa currents are known to underlie synchronized activity in other cortical regions (Corlew et al., 2004). In the spinal motor system, these currents support oscillatory patterns, such as bursts of synchronized waves (Tazerart et al., 2008).

\section{Initiation of synchronized waves}

Although the loci where waves were initiated varied slightly from event to event even in the same slice, the earliest activity emerged mainly from the anterior end of the LEC (Fig. 2B), suggesting that the LEC involves a wave pacemaker. Thus, we sought to isolate the LEC from the whole-brain slices to examine whether the isolated LEC stubs were still capable of emitting autonomous calcium oscillations. The EC was surgically separated into three minislices: (1) the anterior LEC, (2) the border area between the LEC and the MEC, and (3) the posterior MEC (Fig. 2C). Contrary to our expectation, all minislices generated spontaneous waves, although the activity was no longer synchronized among them. The spontaneous activity was commonly observed in minislices prepared from the EC, but virtually not from the other cortical areas. The same results were observed in all minislices prepared from four other rats, suggesting that the EC cortical circuit per se appears to be a self-oscillator, regardless of the EC subareas. The depth of the wave generation sites were $151 \pm 9.45 \mu \mathrm{m}$ from the pial surface ( $n=37$ waves in 5 slices) and were not significantly changed by the dissection $(156 \pm 11.5 \mu \mathrm{m} ; p=0.313, Z=1.01$, Mann-Whitney $U$ test, $n=53$ waves in 5 slices).

To examine whether local neuronal activity in subregions can initiate cortical waves, we returned to whole-brain slices and applied brief electrical stimulation (2 pulses at $40 \mathrm{~Hz}$; pulse duration, $50 \mu \mathrm{s}$; intensity, $40 \mu \mathrm{A}$ ) to four sites: (1) the anterior end of the LEC (the original wave initiation site), (2) the border between the LEC and the MEC, (3) the posterior end of the MEC, and (4) the hippocampal CA1 stratum radiatum (Fig. $3 A$ ). Stimulation of all these sites readily induced synchronized waves that propagated to the entire cortex, similar to spontaneously occurring waves (Fig. $3 B-F$ ), suggesting that any active subregion in the temporal cortical area can trigger cortical waves. However, importantly, the frequency of calcium events was highest in minislices that had originally contained the wave initiation site (Fig. $2 D ; p=0.008, Z=2.65$, Mann-Whitney $U$ test, $n=5$ slices). In the whole brain, therefore, waves may be entrained to the activity of the most active cortical subregion.

To examine the fine-scale neuronal dynamics during the wave initiation, we first identified the locus of the wave initiation using a $1 \times$ objective and then monitored the activity of individual LEC neurons within this locus using a higher-magnification $(16 \times)$ objective (Fig. 4A). The neurons that exhibited the earliest activity during the wave initiation existed in layer III (Fig. $4 B$ ). Subsets of neurons emitted spontaneous calcium activity even under the blockage of fast synaptic transmission in the presence of CNQX, AP5, and picrotoxin (Fig. 4A). This spontaneous activity was completely abolished by TTX ( $n=4$, data not shown) and thus reflected neuronal firing. The proportion of the autonomously active neurons was higher in layer III compared with layer II and $\mathrm{V}$ (Fig. $4 C$; layer II vs III: $p=0.012, Z=2.56$; layer III vs V: $p<$ $10^{-5}, Z=4.38$, Mann-Whitney $U$ test, $n=5$ slices). The activity durations were also the longest in layer III (Fig. $4 D$; layer III vs V: $p<10^{-8}, Z=5.76$, Mann-Whitney $U$ test, $n=5$ slices $)$. One possible explanation for these different properties is the intrinsic circuit organization. A study using pair-recording from EC neurons has demonstrated that the number of intralaminar recurrent connections in layer III is greater than that in layer II (Dhillon and Jones, 2000). The dense, recurrent layer III network may efficiently amplify the spontaneous activity of neurons, which may in turn trigger waves. 

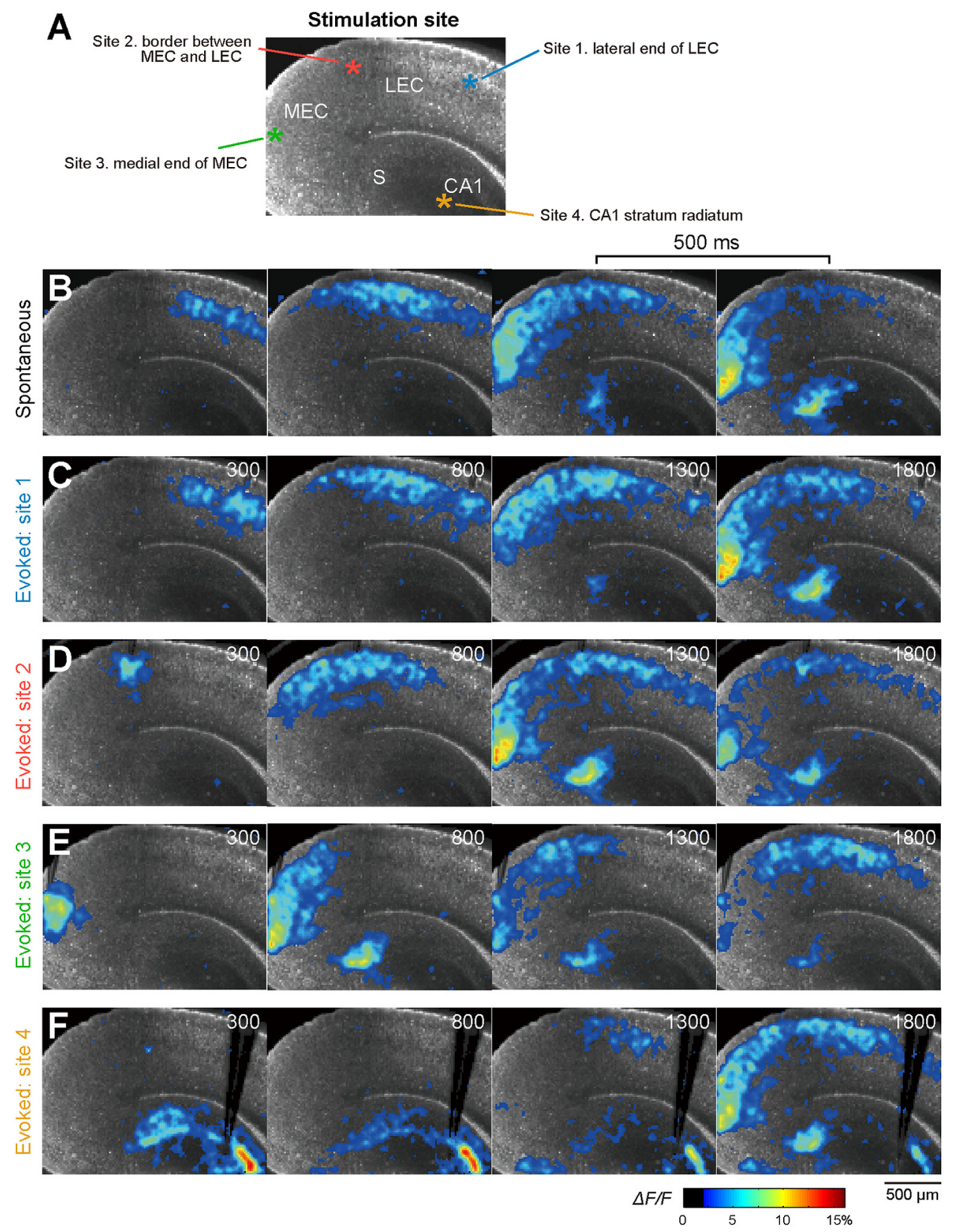

Figure 3. Electrical stimulation-evoked synchronized waves. $\boldsymbol{A}$, Four sites (1-4) of stimulation. $\boldsymbol{B}$, Propagation of a spontaneously generated wave. $\boldsymbol{C}-\boldsymbol{F}$, Waves evoked by electrical stimulation (50 $\mu \mathrm{s}, 40 \mu \mathrm{A}, 2$ pulses) of the lateral end of the LEC ( $\boldsymbol{C}$, site 1), the border between the MEC and LEC ( $\boldsymbol{D}$, site 2), the medial end of the MEC (E, site 3), and the hippocampal CA1 stratum radiatum $(\boldsymbol{F}$, site 4). Stimulation of all sites could induce synchronized waves that propagated beyond the EC. The same results were obtained from all six slices tested.

\section{Propagation of synchronized waves}

We next applied cellular resolution imaging to waves propagating through a posterior part of the LEC (Fig. 5A). We monitored several wave events in the same microscopic field (Fig. 5B) and compared the spatiotemporal patterns of individual cell activation (Fig. 5C,D). In each wave event, the first activated neurons were observed mainly in layer III but also to a lesser extent in layer II (Fig. 5C). Thus, layer III neurons constituted the main leading front of the wave. The orders of cell activation were similar between different waves (Fig. 5D). Spearman's rank correlation coefficients between the neuron sequences were calculated for 76 waves in five slices (Fig. 5E). The mean correlation coefficient was $0.27 \pm 0.43$, and it was significantly biased toward positive values ( $p<10^{-10}, Z=20.7, z$ test for a population mean, $n=76$ waves of 5 slices), indicating that the temporal patterns of sequential cell activation were preserved across wave events.

To further confirm this stereotyped cell activation, we used another statistic, the ratio of "core" cells to the total cells that participated in waves. The core cells were defined as cells that were commonly activated in different waves; note that singlewave events recruited $41.7 \pm 5.6 \%$ of the total numbers of cells ( $n=76$ waves from 5 slices). On average, the core cells contributed 79\% for any given pair of waves in the same slices. This ratio decreased as a function of the number of waves compared and was reduced to $60.2 \%$ in four-wave comparisons (Fig. $6 \mathrm{~A}$, black), but it was consistently higher than the chance level, which was estimated using a resampling method in which all monitored cells, including nonactive cells, were randomly renumbered (Fig. 
A

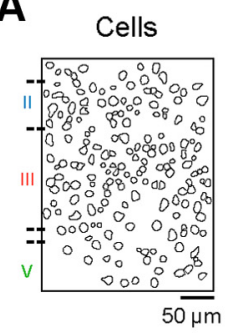

B

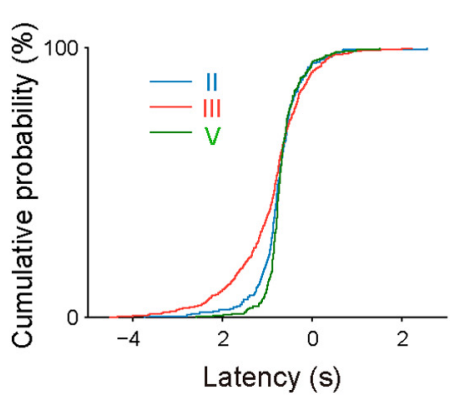

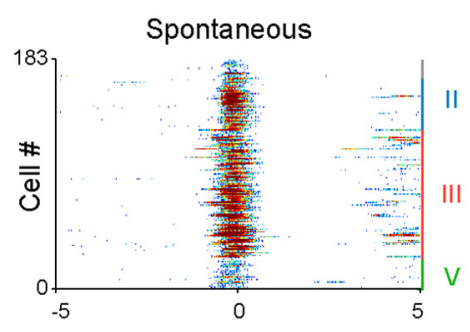

C

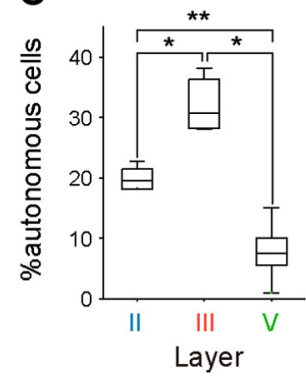

CNQX + AP5 + PTX

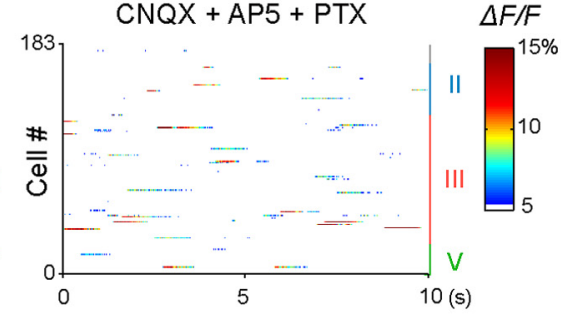

D

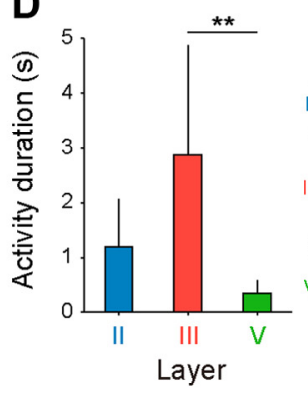

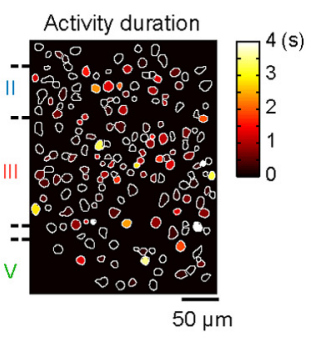

Figure 4. Autonomous cells in LEC layer III. A, Typical raster plot of activity of individual cells (left) in an LEC network before (middle) and after (right) bath application of $20 \mu \mathrm{m}$ CNQX, $50 \mu \mathrm{m}$ AP5, and $100 \mu \mathrm{m}$ picrotoxin (PTX). The wave initiation site was searched using a low-magnification objective (4X) and imaged under high magnification. $\boldsymbol{B}$, Activation of the layer III cells preceded the activation of the other layers ( $p<0.0001$, Kolmogorov-Smirnoff test; $n=3-26$ waves from 6 slices). C, Percentage of autonomously active cells to the total cells monitored in each layer. Data are shown as box plots ${ }^{*} p<0.05,{ }^{* *} p<0.01$, Mann-Whitney $U$ test, $n=5$ slices. $D$, The mean durations of autonomous calcium events were longest in layer III cells. The pseudocolored map (right) indicates the mean event durations in individual cells of the same slice as $A$. Data are means \pm SDs of 5 slices. ${ }^{* *} p<0.01$, Mann-Whitney $U$ test.

6 A, black broken line). Thus, different wave events shared significantly more neurons, shaping the stereotyped internal structure of the waves. We next compared the core cells between spontaneous and stimulation-evoked waves (Fig. $6 B, C$ ). Stimulation of the anterior end of the LEC generated stereotyped waves that reliably recruited a similar population of LEC cells, and the core cell ratio was again significantly higher than expected by chance (Fig. 6A, green). Interestingly, the spontaneous and evoked waves also shared a significant number of cells, and the overlap ratios were almost identical to the levels of "spontaneous versus spontaneous" and "evoked versus evoked" wave comparisons (Fig. 6A, red).

This highly stereotyped activity pattern of propagating waves enabled us to compare glutamatergic and GABAergic synaptic inputs during wave propagation. We conducted whole-cell patch-clamp recordings from LEC layer III neurons ( $n=3$ cells). Glutamatergic and GABAergic PSCs were dominated by clamped voltages at -73 and $0 \mathrm{mV}$, respectively (Fig. 6D). The current traces recorded from the same neuron were averaged over 50 trials of stimulation and plotted in the space of glutamatergic and GABAergic synaptic conductances (Fig. $6 E$ ). We found that these conductances were proportionate during evoked waves, indicating a balanced tuning of the glutamatergic and GABAergic network activity. Furthermore, we conducted dual patch-clamp recordings from adjacent LEC layer III neurons. Three pair types of recording traces [i.e., "glutamatergic vs glutamatergic" $(n=29$ pairs), "GABAergic vs GABAergic" (15 pairs), and "glutamatergic vs GABAergic" (13 pairs)] were compared within the same waves. For all three comparisons, the cross-correlations were biased toward nonzero values, suggesting that neurons received temporally correlated glutamatergic and GABAergic inputs during waves (Fig. 6F).

The intracellular concentration of chloride ions is known to change during development of the cerebral cortex (Luhmann and Prince, 1991; Agmon et al., 1996; Owens et al., 1996; Garaschuk et al., 2000; Yamada et al., 2004; Rheims et al., 2009) and of other areas (Obata et al., 1978; Mueller et al., 1984; Ben-Ari, 2002; Dzhala et al., 2012). This shift in the intracellular environment determines the excitatory or inhibitory action of $\mathrm{GABA}_{\mathrm{A}}$ receptor channels. To examine whether GABA is excitatory or inhibitory in our preparations, we performed local application of $200 \mu \mathrm{M}$ GABA to LEC layer III neurons in the presence of $200 \mu \mathrm{M}$ saclofen, a $\mathrm{GABA}_{\mathrm{B}}$ receptor antagonist (Fig. 6G). GABA induced transient calcium increments in these neurons. In this developmental stage, therefore, LEC is likely to contain a population of neurons on which GABA exerts an excitatory effect.

\section{Termination and reflection of synchronized waves}

We next focused on the wave behavior at the border between the MEC and the parasubiculum. Of 654 waves observed, only eight (1.2\%) propagated into the parasubiculum, and the remaining waves terminated $(70.4 \%)$ or reflected $(28.4 \%)$ at this border ( $n=43$ slices). Figure 7 shows representative cases of terminated (Fig. $7 A, B$ ) and reflected waves (Fig. $7 C, D$ ) in the same slice. Both types of waves were initiated from the anterior LEC (Fig. $7 E, F)$. Similar termination and reflection of waves were observed in aCSF of a different ionic composition with $3.5 \mathrm{~mm}$ potassium ion, $1 \mathrm{~mm}$ magnesium ion, $1.2 \mathrm{~mm}$ calcium ion (see Materials and Methods); the mean frequency in this solution was $5.0 \pm 5.1$ per minute, and $20 \pm 21 \%$ of waves showed reflection $(n=7$ slices at P5-P6).

We monitored calcium wave activity simultaneously with local field potentials (Fig. 7G). Forward waves accompanied single biphasic "sink $\rightarrow$ source" deflections in field potentials (the mean deflection amplitude: $125 \pm 67 \mu \mathrm{V}, n=25$ waves from 5 slices), indicating that they did not reflect network oscillations (Corlew et al., 2004; Allène et al., 2008; Lischalk et al., 2009). Reverse waves after reflection also accompanied biphasic field potentials, but with smaller amplitudes. We did not observe prolonged field activity reported in other studies (Khazipov et al., 2004; Minlebaev et al., 2009, 2011; Sheroziya et al., 2009; Yang et al., 2009). 
A

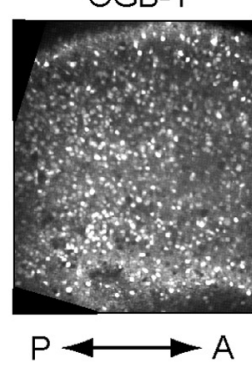

Cells

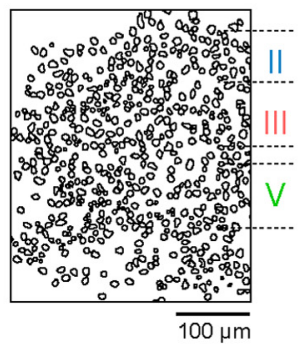

C
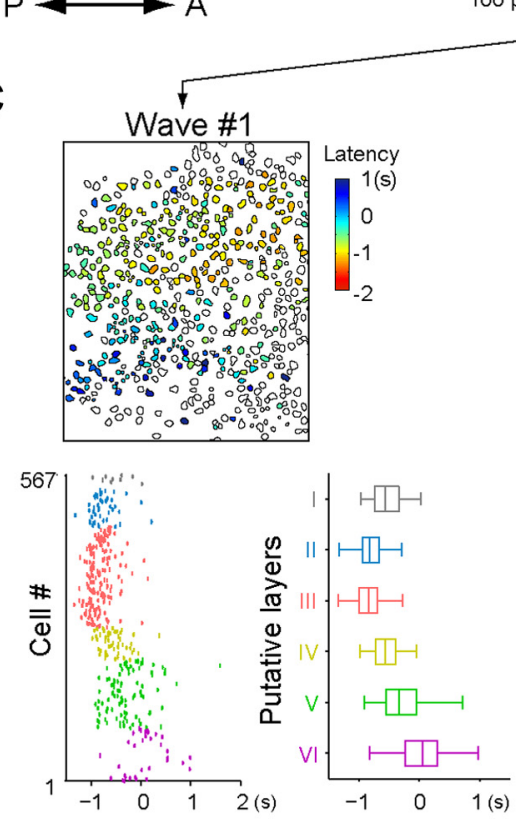

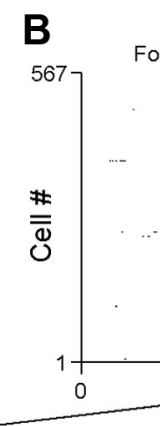

\#1 \#2 \#3
orward Forward Reverse

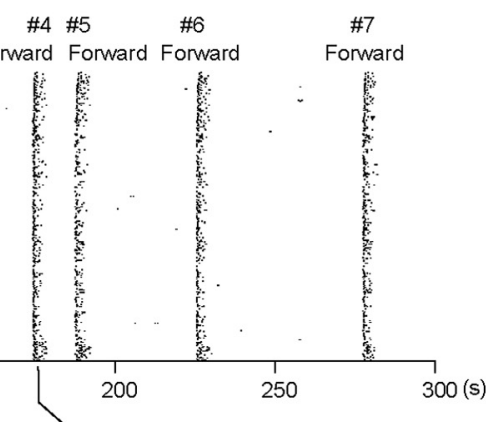

D

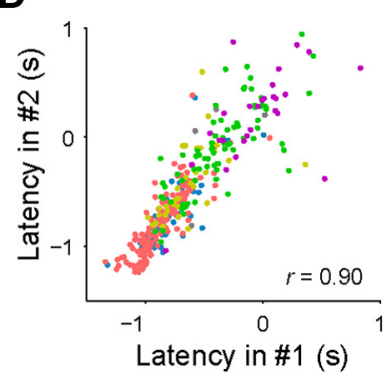

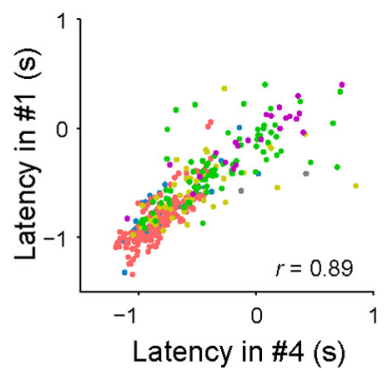

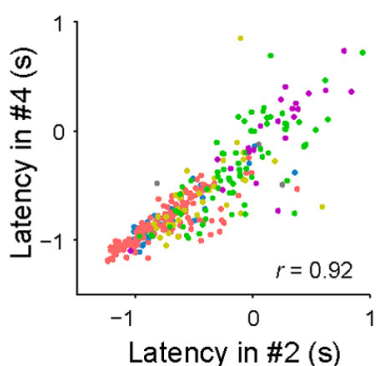

E

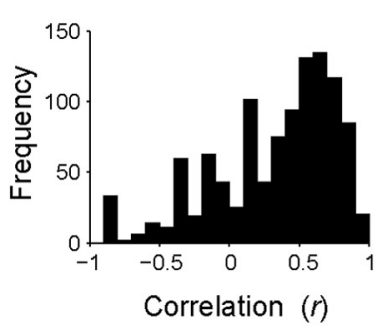

Figure 5. Wave propagation with a leading front in layer III. A, Confocal image of an 0GB1-loaded slice (left) and the locations of 567 cells (right) in the LEC. A, anterior; D, deep; $P$, posterior; $S$, superficial. $\boldsymbol{B}$, Spatiotemporal patterns of multineuronal activity during wave propagation. Each dot indicates the onset of each calcium activity. The data were obtained from the same slice as $\boldsymbol{A}$. Forward, waves propagating in the posterior direction; Reverse, reflected waves propagating in the anterior direction. $\boldsymbol{C}$, Top, Cell maps representing the activity onset in propagating waves \#1, \#2, and \#4 shown in $\boldsymbol{B}$. The onset timing is indicated in a pseudocolored scale. Bottom left, Onset timings of individual cells. The colors indicate the cortical layers. Bottom right, Summarized box plots of the onset timings of neurons in different layers. D, Comparison of the activity latency of individual cells between pairs of wave \#1 versus \#2, \#2 versus \#4, and \#4 versus \#1. Each dot indicates a single cell. The colors represent the layers of cells as shown in $\boldsymbol{C}$. The positive linear correlations indicate that the order of cell activation was largely preserved across waves. $\boldsymbol{E}$, The distribution of Spearman's rank correlation coefficients of the onset timings between all possible pairs of 76 waves in five slices.

The velocities of the waves are shown in line-scan plots corresponding to the tangential axis of the cortex (Fig. $8 A$ ). The forward (or prereflected) waves did not significantly differ in velocity between the cases with and without reflection $(p=0.46$, $Z=0.74$, Mann-Whitney $U$ test, $n=7$ slices), but the reflected waves were slower than their forward waves (Fig. $8 B ; p=0.0024$, $Z=3.04$, Mann-Whitney $U$ test, $n=7$ slices). This difference may be due to the circuit structure (Watt et al., 2009), because the feedback connections in layer III are asymmetrically biased toward the posterior MEC (Beed et al., 2010). Incidentally, the wave propagation was faster in the perirhinal cortex than in the LEC
( $p=0.054, Z=2.87$, Mann-Whitney $U$ test, $n=7$ slices), indicating that the cortex is heterogeneous as a wave medium. Line-scan analyses along the vertical axis of the cortex revealed that both forward and reflected waves were led by layer III (Fig. 8C).

Cellular resolution imaging revealed that nonreflected waves terminated at the border between the MEC and the parasubiculum (Fig. 9A). This border was precise at the single-cell level and exhibited little variation from wave to wave. At this border, neuronal activity during waves was weaker in layer III neurons than in layer II neurons (Fig. 9A). To address the circuit mechanisms of the wave termination, we simultaneously recorded from two 
A

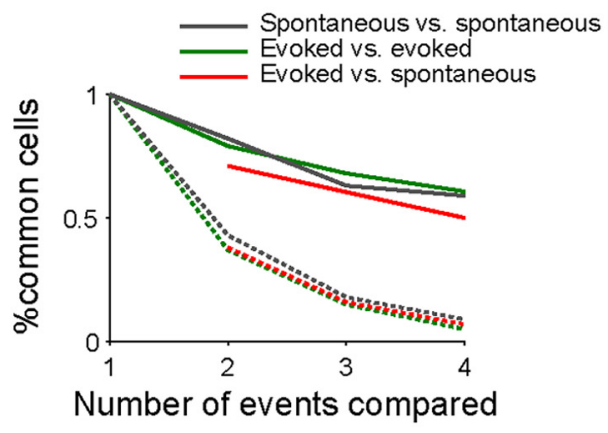

B
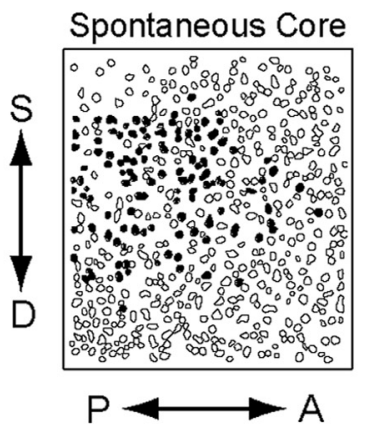
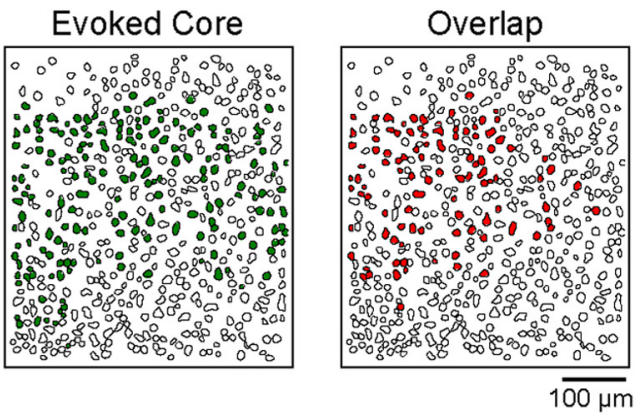

C

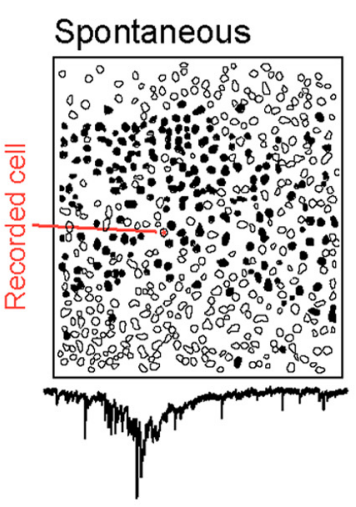

Evoked
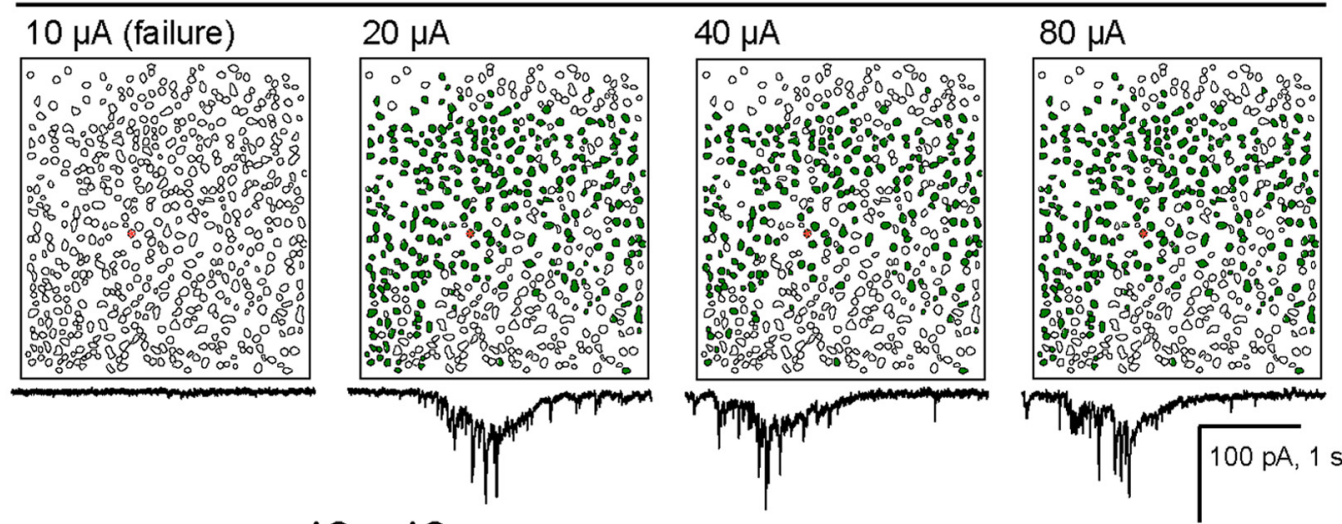

E
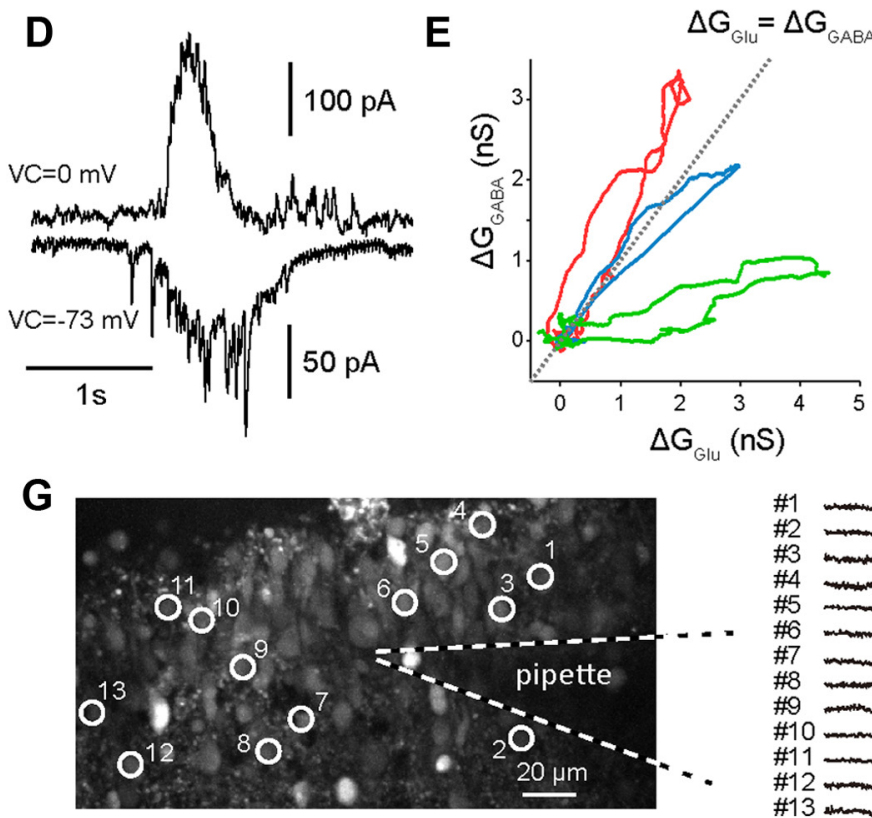

$\mathbf{F}$
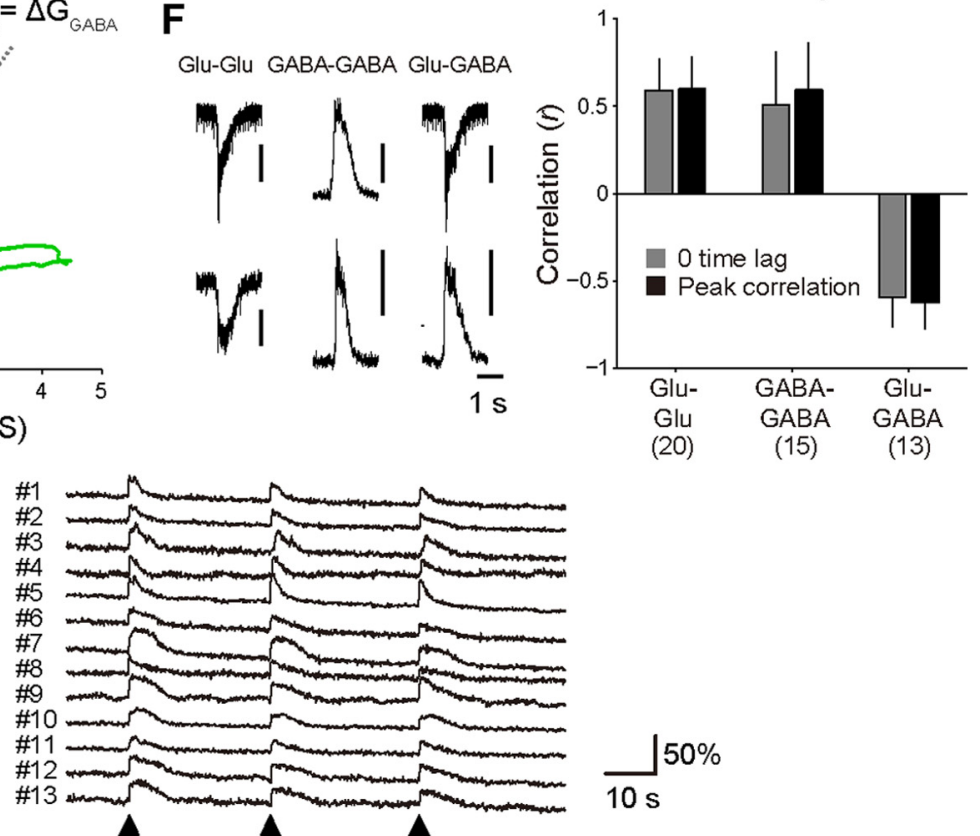

Figure 6. Balanced synaptic inputs during wave propagation. $A$, Ratios of cells commonly activated in 2- 4 different wave events. The evoked waves were generated by field stimulation at intensities of $40 \mu \mathrm{A}$ through a stimulation electrode placed on the lateral end of the LEC. Even pairs of spontaneous and evoked waves shared higher proportions of coparticipants compared with randomly shuffled surrogates (broken line). $n=26$ waves from three slices. $\boldsymbol{B}$, Maps of active cells of spontaneous and stimulation-evoked waves. The cells that participated in all monitored events were defined as core cells. The core populations shared by the spontaneous and evoked waves are indicated in the map on the left. A, anterior; D, deep; P, posterior; S, superficial. C, Voltage-clamp recordings (bottom) from an MEC layer III neuron (red asterisk) during spontaneous and LEC stimulation-evoked waves (top). Waves were elicited by LEC stimulation at intensities of $10-80 \mu A$. The holding potential was $-73 \mathrm{mV}$. Similar barrages of synaptic inputs were observed during spontaneous and evoked waves. Small synaptic inputs preceded the barrage inputs, indicating the existence of feedforward input. D, Representative traces (left) of synaptic currents recorded at -73 and $0 \mathrm{mV}$. $\boldsymbol{E}$, Time evolution of glutamatergic and GABAergic synaptic inputs. Both conductances were positively correlated during a wave (right). The data were obtained from three neurons from three slices, and different colored traces represent different cells. $\boldsymbol{F}$, Correlated synaptic currents between adjacent pairs of EC neurons. Cross-correlations between the neuron pairs were calculated for glutamatergic and/or GABAergic synaptic inputs without ( 0 time lag) and with time alignment at the current peak (peak correlation). Data are means \pm SDs of 29,13 , and 14 pairs. Representative raw traces are shown in the left inset. Scale bars, 40 pA for glutamatergic and 100 pA for GABAergic inputs. G, GABA-induced calcium activity in EC neurons. Raw calcium traces shown by 13 representative neurons in the left photograph are presented. Arrowheads indicate the times of puff application of $200 \mu \mathrm{m}$ GABA. 

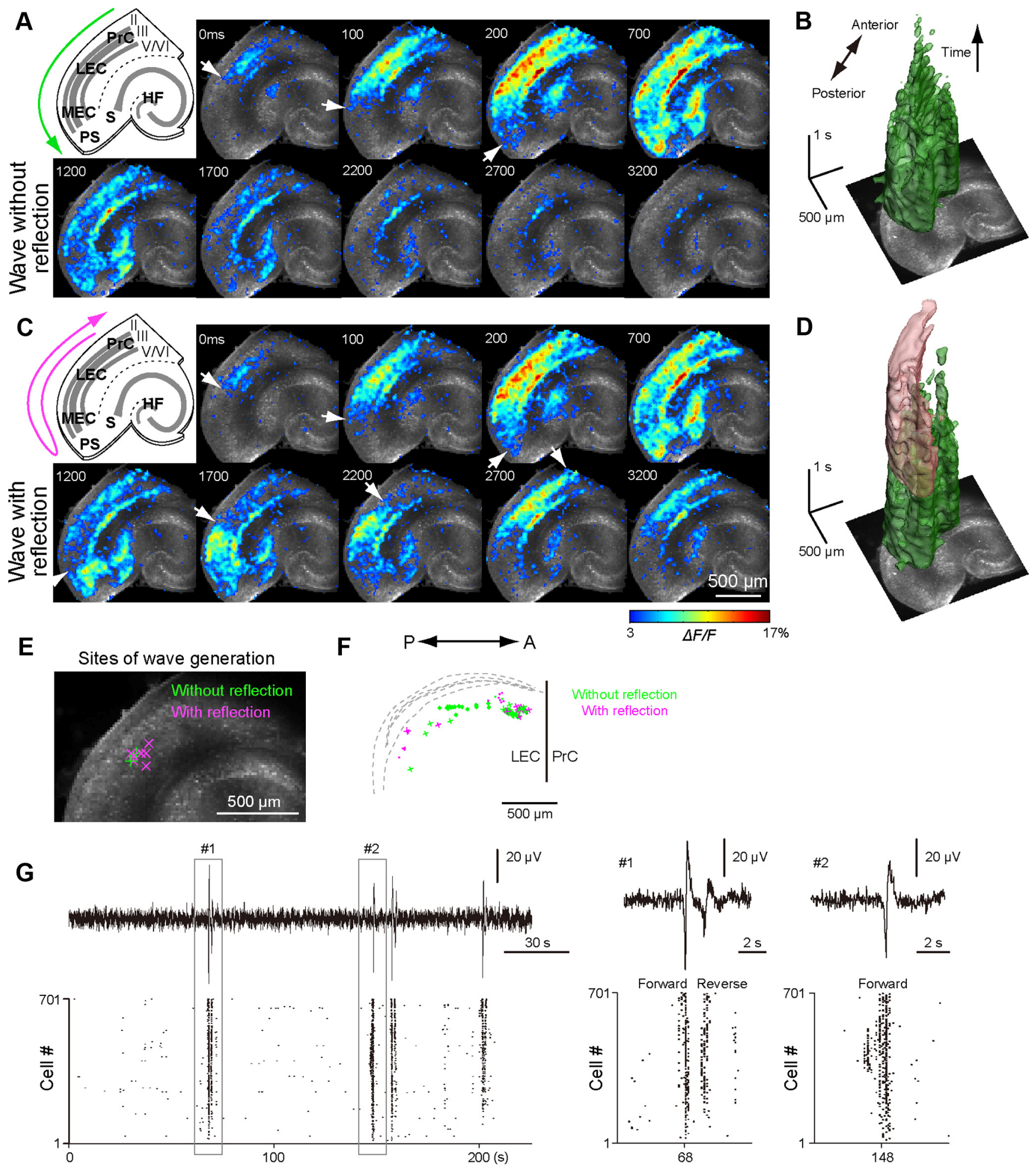

Without reflection

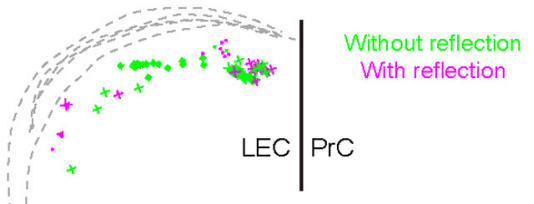

$500 \mu \mathrm{m}$

Figure 7. Termination and reflection of synchronized waves in the MEC. A, Example time-lapse images of a synchronized wave without reflection. The wave was initiated at the lateral end of the LEC and propagated bidirectionally in a tangential direction. The posterior wave terminated at the border between the MEC and the parasubiculum (PS), with a small wave entering the subiculum (S). HF, hippocampal formation; PrC, perirhinal cortex. The wave fronts are indicated by arrows. $\boldsymbol{B}$, The wave in $\boldsymbol{A}$ is plotted in the xyt form. Fluorescence changes $>3 \%$ were detected and reconstructed along the time (vertical) axis. $\boldsymbol{C}$, Example of a synchronized wave with reflection. The data were obtained from the same slice as $\boldsymbol{A}$. The wave that reached the border between the MEC and the parasubiculum changed the direction of propagation and generated a reflected wave. $\boldsymbol{D}, x y t$ plot of the wave in $\boldsymbol{C}$. The transparent red area indicates the reflected wave. $\boldsymbol{E}$, The initiation sites (the mass centers of the earliest activated areas) of individual waves in the same slice are compared between waves without reflection (green) and with reflection (magenta). $\boldsymbol{F}$, The initiation sites of all nonreflected and reflected waves observed in five slices are superimposed after spatial alignment to the rhinal sulcus. G, Simultaneous monitoring of somatic calcium signals and field potentials. Two wave events (\#1 and \#2) were magnified in two right panels. Top, Spontaneous field potential. Bottom, Reconstructed neuronal activity. 

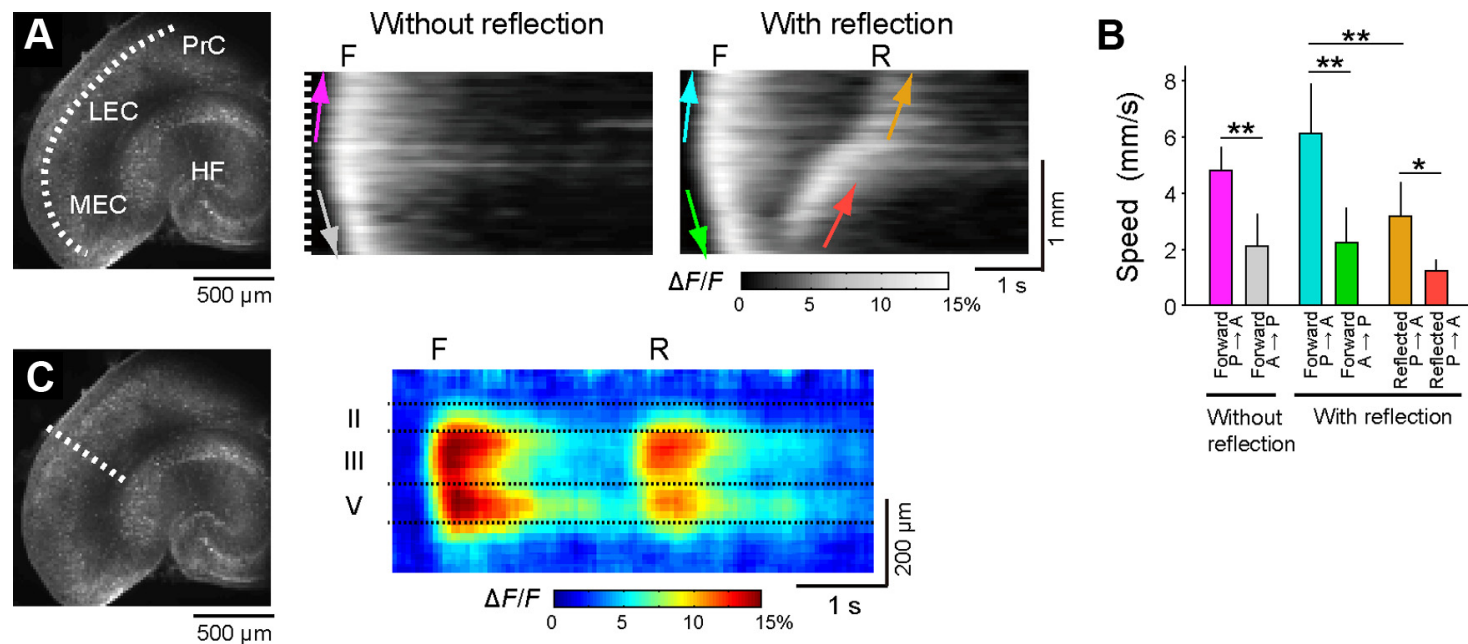

reflection

Figure 8. Dynamics of forward and reflected synchronized waves. $A$, Confocal image of an OGB1-loaded slice (left). The dotted line was line-scanned in waves without reflection (middle) and with reflection (right). HF, hippocampal formation; $\operatorname{PrC}$, perirhinal cortex. F, forward waves; $R$, reflected waves. $B$, Propagation speeds of waves in the $\operatorname{PrC}$ (forward from posterior to anterior, $P \rightarrow A$; reflection from posterior to anterior, $P \rightarrow A$ ) and the $M E C$ (forward from anterior to posterior, $A \rightarrow P$; reflection from posterior to anterior, $P \rightarrow A$ ). The colors of the columns correspond to those of the arrows shown in $\boldsymbol{A}$. Error bars represent SDs of seven slices. ${ }^{*} p<0.05,{ }^{* *} p<0.01$; Mann-Whitney $U$ test. $C$, The dotted line of an 0GB1-loaded slice (left) was line-scanned during forward and reflected waves. In both waves, layer III was activated earlier than the other layers. F, forward waves; $R$, reflected waves.
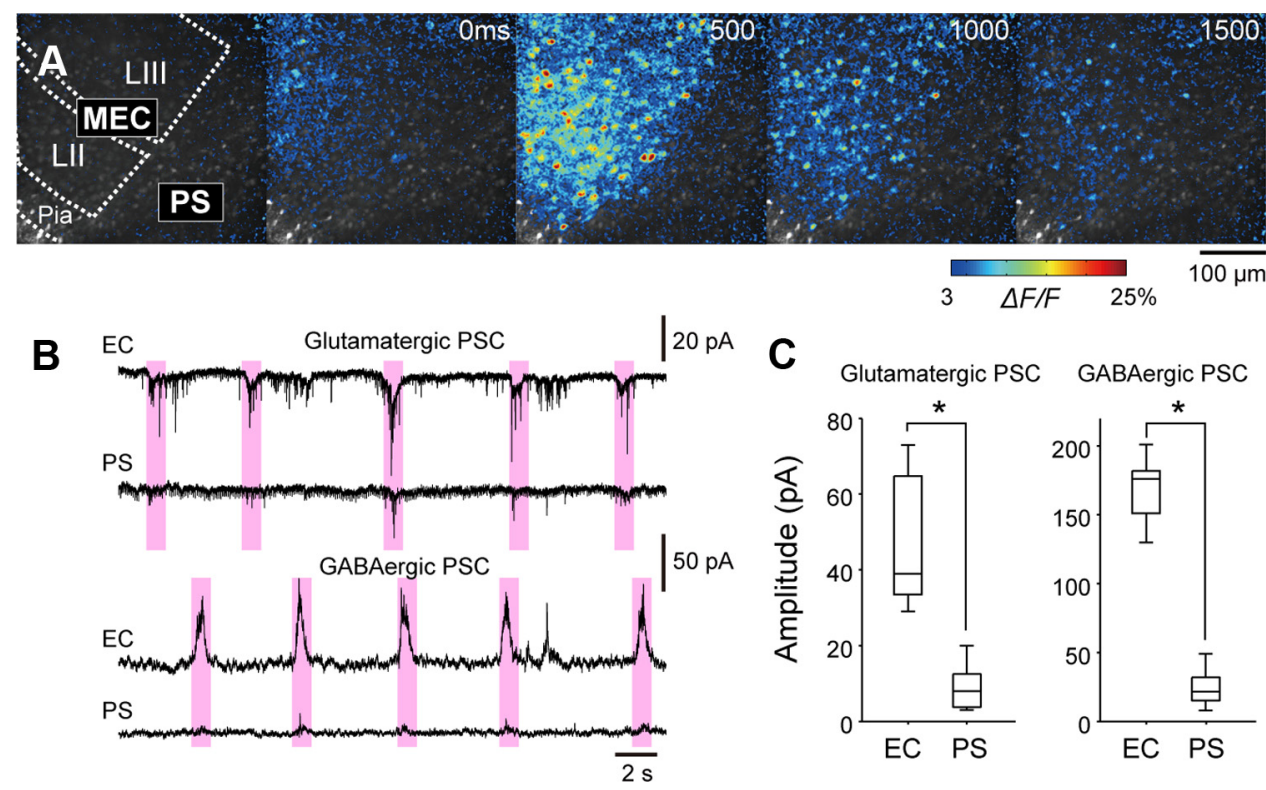

Figure 9. Wave termination in the MEC. A, High-magnification imaging of a wave that stopped at the border between the MEC and the parasubiculum (PS). The MEC layer II neurons were more active than the layer III neurons. $\boldsymbol{B}$, Simultaneous voltage-clamp recording from two pyramidal cells in the MEC and parasubiculum (PS) during wave termination. Glutamatergic PSCS (top) and GABAergic PSCs (bottom) were dominated at clamped voltages of -73 and $0 \mathrm{mV}$. The shaded areas indicate the periods of wave-relevant activation. $\boldsymbol{C}$, The peak amplitudes of wave-relevant glutamatergic PSCs (left) and GABAergic PSCs (right) in the MEC were larger than those in the parasubiculum. Data are shown as box plots. ${ }^{*} p<0.05$, Mann-Whitney $U$ test, $n=5$ and 6 cells from a total of six slices for glutamatergic PSCs and GABAergic PSCs, respectively.

patched neurons in the MEC layer II and the parasubiculum (Fig. $9 B$ ). The MEC neurons received large glutamatergic and GABAergic PSCs during the arrival of the waves, but the parasubicular neurons received substantially smaller synaptic inputs (Fig. $9 C$; glutamatergic PSCs: $p=0.0078, Z=2.66, n=5$ neurons from 5 slices; GABAergic PSCs: $p=0.0022, Z=3.07, n=6$ neurons from 6 slices, Mann-Whitney $U$ test). Thus, the synaptic influences of the EC on parasubicular networks are weak, and the MEC and the parasubiculum are functionally segregated, at least at this early developmental stage.

The border dynamics of nonreflected and reflected waves were different at the cellular level (Fig. 10A). In a reflected wave, the calcium activity of the MEC layer II neurons disappeared after the forward wave arrived and reappeared at the initiation time of the reflected wave; however, some of the layer III neurons were found to show persistent activity during the entire period of wave arrival and reflection (Fig. 10B). Consistent with this observation, the layer II and III neurons received two-peaked and prolonged synaptic barrages, respectively (Fig. 10C). The total duration of the barrages in the layer II neurons during wave reflection was significantly shorter than that of the layer III neurons (Fig. $10 D$, red; $p=0.0078, Z=2.66, n=5$ neurons from 5 slices, Mann-Whitney $U$ test). Even during nonreflected waves, the barrage duration in layer II was still shorter than that in layer 

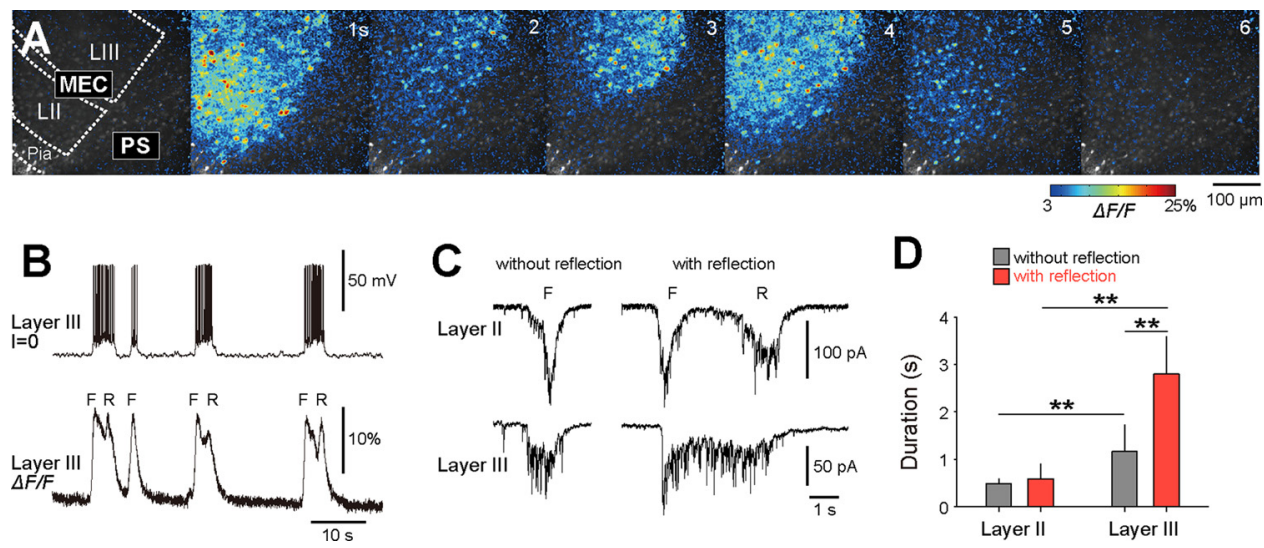

Figure 10. Persistent synaptic inputs into the MEC layer III neurons during wave reflection. $\boldsymbol{A}$, High-magnification imaging of a wave that reflected at the border between the MEC and the parasubiculum (PS). When compared with the case of wave termination (Fig. 9A), cells in the MEC layer III were more strongly activated; note that during and after a transient decrease in the entire activity of $\sim 2 \mathrm{~s}$, the layer III activity persisted from 2 to $4 \mathrm{~s}$. Following this persistent activation of layer III cells, the second wave was generated at $4 \mathrm{~s}$, and the network became silent by $6 \mathrm{~s}$. B, Simultaneous recording of the membrane potential (top) and the calcium fluorescence (bottom) of an MEC layer III neuron. F, forward waves; R, reflected waves. C, Representative glutamatergic PSC traces recorded simultaneously from an MEC layer II cell (top) and a layer III cell (bottom) during wave termination (left) and wave reflection (right). The layer III neuron received prolonged synaptic inputs during wave reflection. $D$, The PSC durations in layer III neurons were longer than those in layer II neurons and longer during wave reflection (reflected) than during wave termination (stop). The duration was calculated as a 25\%-peak width of synaptic barrages. Error bars represent SDs of five, five, six, and five neurons from six slices. ${ }^{*} p<0.05$, ${ }^{* *} p<0.01$, Mann-Whitney $U$ test.

III (Fig. $10 D$, gray; $p=0.017, Z=2.38, n=5-6$ neurons from 5 to 6 slices, Mann-Whitney $U$ test).

To examine what determines the termination or reflection of waves, we measured the peak amplitudes of wave-relevant calcium signals from the border area of the MEC and LEC through which the wave propagated. Forward waves that thereafter exhibited reflection had larger calcium signals than nonreflected forward waves (Fig. $11 A ; p=0.027, Z=2.20$, Wilcoxon signed-rank test, $n=6$ slices). This larger calcium signal was likely to reflect the stronger spiking activity of the neurons because whole-cell recordings from layer III neurons near the border area of the MEC and LEC revealed that the maximal firing frequencies and the total spike numbers during the forward waves were both higher in the reflected waves than in the nonreflected waves (Fig. $11 B$; firing rate: $p=0.043, Z=2.02$; spike number: $p=0.043$, $Z=2.02$, Wilcoxon signed-rank test, $n=5$ neurons of 5 slices). To examine whether the stronger activation of neurons during a wave was sufficient to induce reflection, we stimulated the anterior LEC at different stimulus intensities. Stimulation at $>10 \mu \mathrm{A}$ reliably evoked cortical waves (Fig. 11C,D, black), and stimulation with higher intensities induced waves with higher fluorescence increases (Fig. 11C). We found that strong stimulation at $80 \mu \mathrm{A}$ induced wave reflection with a significantly higher probability than chance (Fig. $11 D$, red; $p=0.0011$ vs $5 \mu \mathrm{A}$ stimulus, $Z=3.07$, Mann-Whitney $U$ test, $n=4$ slices).

\section{Discussion}

In this work, we described macroscopic and microscopic behaviors of synchronized spike waves in immature cortical networks, including the initiation, propagation, termination, and reflection of these waves. We found that layer III neurons played key roles in these wave behaviors.

\section{Initiation of synchronized waves}

Low-magnification monitoring revealed that early spontaneous activity was not confined to local events but instead represented globally synchronized waves that propagated throughout the entire cortex. We also identified the anterior end of the LEC as the main start point of the waves. It is intriguing to find that in adulthood, the EC acts as the cortical hub that connects the hip- pocampus with other parts of the cerebral cortex (Squire and Zola-Morgan, 1988; Felleman and Van Essen, 1991); sensory inputs are partially integrated at the perirhinal and postrhinal cortices after multistep relays in various brain areas and conveyed to the hippocampus through the EC (Burwell and Amaral, 1998a,b; Burwell, 2001). It has been demonstrated that the posterior part of the developing brain is the source of early synchronized waves (Garaschuk et al., 2000; Momose-Sato et al., 2012). We confirmed this observation and further identified layer III of the LEC as a wave-initiating zone. Sheroziya et al. (2009) have reported intermittent electrical activity in the developing EC. These authors described two types of spontaneous field potential activity, referred to as field potential sharp and field potential burst. Based on the event frequency and the pharmacological profiles, we speculate that field potential sharps correspond to single forward waves described here, whereas we could not identify the neural correlate of field potential bursts.

The source of synchronized waves in vivo is unknown. A human neonatal EEG study showed that the origin of the waves was a posterior region of the cortex (Dreyfus-Brisac and Larroche, 1971). In contrast, slow-wave oscillations, a putative counterpart of the waves in adulthood (Rochefort et al., 2009), arise primarily from the anterior part of the cortex (Massimini et al., 2004; Isomura et al., 2006; Minamisawa et al., 2009). Thus, the pacemaker for synchronized waves is likely to shift from the posterior cortex to the anterior cortex during development.

\section{Termination and reflection of synchronized waves}

The functional border where cortical waves terminated displayed a precise anatomical line that corresponded to the border between the MEC and the parasubiculum. The wave termination can be explained by two possibilities: (1) sparse neuronal connectivity or (2) strong GABAergic projections from the MEC to the parasubiculum. Using double patch-clamp recordings, we showed that in either glutamatergic PSCs or GABAergic PSCs, wave-relevant MEC activity was not transmitted to parasubicular neurons. Thus, the first possibility is more likely.

Cortical waves exhibited two distinct border behaviors: termination and reflection. Two important findings are as follows: (1) a population of MEC layer III neurons exhibited persistent firing 
activity when reflection occurred, and (2) stronger stimulation resulted in a higher probability of generating the wave reflection. Based on these observations, we hypothesize the following scenario:

1. Stronger activation in the wavegeneration network triggers stronger waves. In other words, the intensity of the wave-initiating activity is registered in the propagating wave activity. This idea is consistent with our finding that stronger stimulation evoked forward waves that exhibited higher fluorescence intensities.

2. Strong activity during forward waves causes the sustained firing of layer III neurons at the border, leading to reactivation of layer II neurons and the generation of reflected waves. In this scenario, the persistent activity of layer III neurons serves as a short-term memory trace during wave reflection.

Cortical waves reflected reproducibly at the identical functional border. A theoretical study suggests that the spatial difference of the wave media causes the reflection of propagating waves (Ermentrout and Rinzel, 1996). The circuit excitability and inhibitability are candidate quantities to determine the refraction index or permeability coefficient of the media. Xu et al. (2007) reported that GABAergic inhibition is crucial in wave compression and reflection in the visual cortex. However, computational studies propose that manipulation of the threshold and the recurrent excitation is different during compression and reflection (Ermentrout and Rinzel, 1996; Goulet and Ermentrout, 2011). In general, when a wave is transferred from the excitable medium A to the less excitable medium B, a conduction delay occurs because of the weaker excitability. If the delay is long enough, medium $\mathrm{A}$ is reactivated when medium $B$ is activated, thus medium A generates an additional wave moving the opposite direction (Ermentrout and Rinzel, 1996). We did not observe wave compression at the border between the MEC and the parasubiculum; indeed, we rarely encountered waves that propagated into the parasubiculum. In our experimental preparations, therefore, the delay is considered almost infinitely long (Ermentrout and Rinzel, 1996). We thus propose that persistent activity of layer III neurons works to support the delay that can eventually re-excite the MEC network.

\section{Comparison with waves that occur in coronal slices}

Large-scale wave dynamics have been also studied in coronal slices of mice (Lischalk et al., 2009; Conhaim et al., 2010, 2011).

B Mann-Whitney $U$ test.
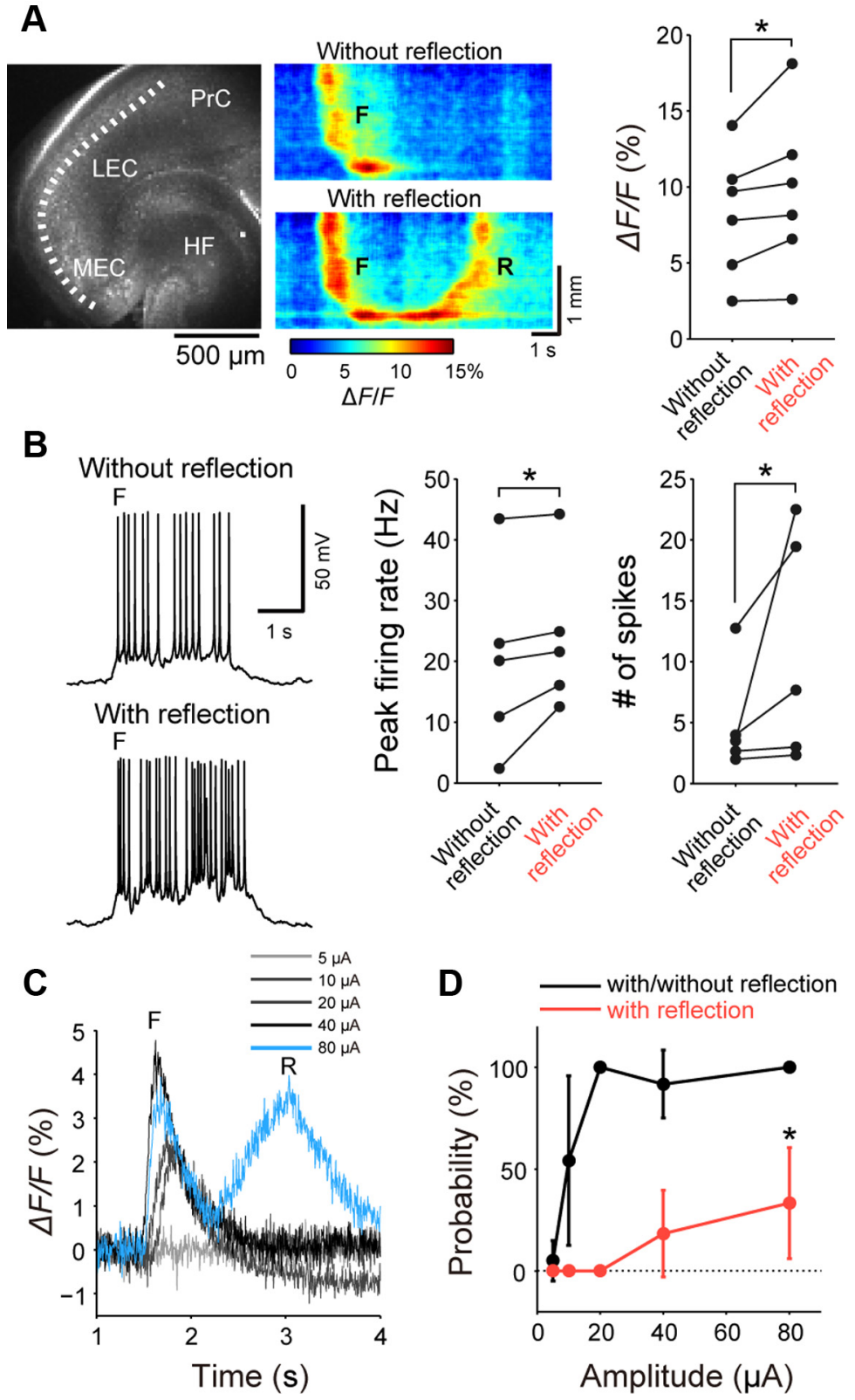

Figure 11. Effect of wave intensity on the reflection probability. $\boldsymbol{A}$, The peak $\Delta F / F$ amplitudes of the forward waves with reflection were larger than in the nonreflected forward waves. Left, The calcium signal was measured from the border area of the MEC and the LEC where the forward wave propagated through. F, forward waves; $R$, reflected waves. ${ }^{*} p<0.05$, Wilcoxon signed-rank test, $n=6$ slices. $\boldsymbol{B}$, The maximal firing frequencies and the total spike numbers of layer III neurons near the border area of the MEC and the LEC during the forward waves were higher in the reflected waves than in the nonreflected waves. ${ }^{*} p<$ 0.05 , Wilcoxon signed-rank test, $n=5$ neurons of five slices. $C$, Representative population calcium signal of waves initiated by electrical stimulation of the LEC at $5-80 \mu \mathrm{A}(250 \mu \mathrm{s}$ pulses at $40 \mathrm{~Hz})$ at time $0 \mathrm{~s}$. D. Probability of the stimulation-induced initiation of waves (black) and reflected waves (red) for the 30 stimulation trials. Error bars represent SDs of four slices. ${ }^{*} p<0.05$,

Although the event frequency of waves in horizontal slices is similar to that of coronal slices, ranging from 1 to 5 per minute (McCabe et al., 2006; Allène et al., 2008; Conhaim et al., 2010, 2011), there are three major differences: (1) the initiation sites of waves, (2) dependence on $\mathrm{GABA}_{\mathrm{A}}$ receptors, and (3) spatiotemporal dynamics of wave propagation.

First, the initiation sites of the waves are different (Lischalk et al., 2009). The ventral area of the brain tends to be the wavegeneration site in coronal slices (Lischalk et al., 2009; Conhaim et al., 2011). It should be noted, however, that this is still consistent 
with our data obtained in horizontal slices of the ventral brain; we succeeded in observing cortical waves only in slices prepared from the ventral brain. Second, waves are sensitive to the application of the picrotoxin in some studies (Conhaim et al., 2011), but not in P5-P6 rats in the present study nor in other studies (Garaschuk et al., 2000). As discussed in Conhaim et al. (2011), GABA and glutamate have different effects on rat and mouse cortical neuronal migration (Behar et al., 1999). Thus, there may be a species difference in the mechanisms of the waves. Third, waves triggered by the septum have been reported in mice (Conhaim et al., 2010), whereas we observed only intracortical waves. In mice, the septum can activate the cortical pacemakers, resulting in bilaterally synchronized waves without a time lag (Conhaim et al., 2010). In horizontal slices used in the present study, bilateral waves had a small time lag. Because our slice preparations contain the corpus callosum and the anterior commissure (Horel and Stelzner, 1981; Paxinos and Watson, 1998), these interhemispheric fibers are candidates that mediate the delayed correlations of bilateral cortical waves.

\section{Technical considerations}

A recent paper reports that neurons near the surface of acute slices in developing mice show an increased intracellular concentration of chloride ion (Dzhala et al., 2012), enhancing the excitatory action of GABA. This could cause the wave generation. In the present study, however, bath application of picrotoxin did not affect the event frequency of waves, suggesting that our cortical waves are attributable to glutamatergic, but not GABAergic, synaptic transmission. Therefore, even if GABA was anomalously excitatory in our immature brain slices, this would not strongly affect our data and data interpretation; note that several recent papers reported that early network oscillations in the cortex do not rely on the excitatory action of GABA (Bregestovski and Bernard, 2012; Dzhala et al., 2012). However, we do not exclude the possibility that GABAergic synapses may modulate the biological aspects of wave dynamics in vivo, such as speed and the probability of reflection.

We believe that the basic properties of cortical waves in acute brain slices replicated those in the in vivo brain, because some physiological properties, such as the wave frequency (Adelsberger et al., 2005) and the pharmacological profiles (Minlebaev et al., 2009), were similar between the present study and previous in vivo works. Some of the experiments that we performed here are difficult to be done under in vivo conditions. First, the combination of wide-field-resolution and single-cell-resolution imaging allowed us to identify the exact locations where waves arise, terminate, and reflect. Second, simultaneous imaging from different layers revealed the importance of layer III cells. Third, dual patch-clamp recording revealed the circuit mechanisms that support the wave propagation, termination, and reflection. Thus, our experimental system will provide useful information that complements the in vivo works.

\section{References}

Adelsberger H, Garaschuk O, Konnerth A (2005) Cortical calcium waves in resting newborn mice. Nat Neurosci 8:988-990. CrossRef Medline

Agmon A, Hollrigel G, O’Dowd DK (1996) Functional GABAergic synaptic connection in neonatal mouse barrel cortex. J Neurosci 16:4684-4695. Medline

Allène C, Cattani A, Ackman JB, Bonifazi P, Aniksztejn L, Ben-Ari Y, Cossart R (2008) Sequential generation of two distinct synapse-driven network patterns in developing neocortex. J Neurosci 28:12851-12863. CrossRef Medline
Arieli A, Sterkin A, Grinvald A, Aertsen A (1996) Dynamics of ongoing activity: explanation of the large variability in evoked cortical responses. Science 273:1868-1871. CrossRef Medline

Bao W, Wu JY (2003) Propagating wave and irregular dynamics: spatiotemporal patterns of cholinergic theta oscillations in neocortex in vitro. J Neurophysiol 90:333-341. CrossRef Medline

Beed P, Bendels MH, Wiegand HF, Leibold C, Johenning FW, Schmitz D (2010) Analysis of excitatory microcircuitry in the medial entorhinal cortex reveals cell-type-specific differences. Neuron 68:1059-1066. CrossRef Medline

Behar TN, Scott CA, Greene CL, Wen X, Smith SV, Maric D, Liu QY, Colton CA, Barker JL (1999) Glutamate acting at NMDA receptors stimulates embryonic cortical neuronal migration. J Neurosci 19:4449-4461. Medline

Ben-Ari Y (2001) Developing networks play a similar melody. Trends Neurosci 24:353-360. CrossRef Medline

Ben-Ari Y (2002) Excitatory actions of gaba during development: the nature of the nurture. Nat Rev Neurosci 3:728-739. CrossRef Medline

Benucci A, Frazor RA, Carandini M (2007) Standing waves and traveling waves distinguish two circuits in visual cortex. Neuron 55:103-117. CrossRef Medline

Blankenship AG, Feller MB (2010) Mechanisms underlying spontaneous patterned activity in developing neural circuits. Nat Rev Neurosci 11:18 29. CrossRef Medline

Bolea S, Sanchez-Andres JV, Huang X, Wu JY (2006) Initiation and propagation of neuronal coactivation in the developing hippocampus. J Neurophysiol 95:552-561. Medline

Bregestovski P, Bernard C (2012) Excitatory GABA: How a correct observation may turn out to be an experimental artifact. Front Pharmacol 3:65. Medline

Burwell RD (2001) Borders and cytoarchitecture of the perirhinal and postrhinal cortices in the rat. J Comp Neurol 437:17-41. CrossRef Medline

Burwell RD, Amaral DG (1998a) Perirhinal and postrhinal cortices of the rat: interconnectivity and connections with the entorhinal cortex. J Comp Neurol 391:293-321. CrossRef Medline

Burwell RD, Amaral DG (1998b) Cortical afferents of the perirhinal, postrhinal, and entorhinal cortices of the rat. J Comp Neurol 398:179_ 205. CrossRef Medline

Calderon DP, Leverkova N, Peinado A (2005) Gq/11-induced and spontaneous waves of coordinated network activation in developing frontal cortex. J Neurosci 25:1737-1749. CrossRef Medline

Colonnese MT, Kaminska A, Minlebaev M, Milh M, Bloem B, Lescure S, Moriette G, Chiron C, Ben-Ari Y, Khazipov R (2010) A conserved switch in sensory processing prepares developing neocortex for vision. Neuron 67:480-498. CrossRef Medline

Conhaim J, Cedarbaum ER, Barahimi M, Moore JG, Becker MI, Gleiss H, Kohl C, Moody WJ (2010) Bimodal septal and cortical triggering and complex propagation patterns of spontaneous waves of activity in the developing mouse cerebral cortex. Dev Neurobiol 70:679-692. CrossRef Medline

Conhaim J, Easton CR, Becker MI, Barahimi M, Cedarbaum ER, Moore JG, Mather LF, Dabagh S, Minter DJ, Moen SP, Moody WJ (2011) Developmental changes in propagation patterns and transmitter dependence of waves of spontaneous activity in the mouse cerebral cortex. J Physiol 589:2529-2541. CrossRef Medline

Corlew R, Bosma MM, Moody WJ (2004) Spontaneous, synchronous electrical activity in neonatal mouse cortical neurones. J Physiol 560:377-390. CrossRef Medline

Crépel V, Aronov D, Jorquera I, Represa A, Ben-Ari Y, Cossart R (2007) A parturition-associated nonsynaptic coherent activity pattern in the developing hippocampus. Neuron 54:105-120. CrossRef Medline

Dhillon A, Jones RS (2000) Laminar differences in recurrent excitatory transmission in the rat entorhinal cortex in vitro. Neuroscience 99:413422. CrossRef Medline

Dreyfus-Brisac C, Larroche JC (1971) Discontinuous electroencephalograms in the premature newborn and at term. Electro-anatomo-clinical correlations (in French). Rev Electroencephalogr Neurophysiol Clin 1:95-99. Medline

Dzhala V, Valeeva G, Glykys J, Khazipov R, Staley K (2012) Traumatic alterations in GABA signaling disrupt hippocampal network activity in the developing brain. J Neurosci 32:4017-4031. CrossRef Medline 
Egorov AV, Hamam BN, Fransén E, Hasselmo ME, Alonso AA (2002) Graded persistent activity in entorhinal cortex neurons. Nature 420:173178. CrossRef Medline

Ermentrout GB, Kleinfeld D (2001) Traveling electrical waves in cortex: insights from phase dynamics and speculation on a computational role. Neuron 29:33-44. CrossRef Medline

Ermentrout GB, Rinzel J (1996) Reflected waves in a inhomogeneous excitable medium. SIAM J Appl Math 56:1107-1128. CrossRef

Felleman DJ, Van Essen DC (1991) Distributed hierarchical processing in the primate cerebral cortex. Cereb Cortex 1:1-47. CrossRef Medline

Fransén E, Tahvildari B, Egorov AV, Hasselmo ME, Alonso AA (2006) Mechanism of graded persistent cellular activity of entorhinal cortex layer v neurons. Neuron 49:735-746. CrossRef Medline

Garaschuk O, Linn J, Eilers J, Konnerth A (2000) Large-scale oscillatory calcium waves in the immature cortex. Nat Neurosci 3:452-459. CrossRef Medline

Golshani P, Gonçalves JT, Khoshkhoo S, Mostany R, Smirnakis S, PorteraCailliau C (2009) Internally mediated developmental desynchronization of neocortical network activity. J Neurosci 29:10890-10899. CrossRef Medline

Goulet J, Ermentrout GB (2011) The mechanisms for compression and reflection of cortical waves. Biol Cybern 105:253-268. CrossRef Medline

Han F, Caporale N, Dan Y (2008) Reverberation of recent visual experience in spontaneous cortical waves. Neuron 60:321-327. CrossRef Medline

Horel JA, Stelzner DJ (1981) Neocortical projections of the rat anterior commissure. Brain Res 220:1-12. CrossRef Medline

Huang X, Xu W, Liang J, Takagaki K, Gao X, Wu JY (2010) Spiral wave dynamics in neocortex. Neuron 68:978-990. CrossRef Medline

Ikegaya Y, Aaron G, Cossart R, Aronov D, Lampl I, Ferster D, Yuste R (2004) Synfire chains and cortical songs: temporal modules of cortical activity. Science 304:559-564. CrossRef Medline

Ikegaya Y, Le Bon-Jego M, Yuste R (2005) Large-scale imaging of cortical network activity with calcium indicators. Neurosci Res 52:132-138. CrossRef Medline

Isomura Y, Sirota A, Ozen S, Montgomery S, Mizuseki K, Henze DA, Buzsáki G (2006) Integration and segregation of activity in entorhinalhippocampal subregions by neocortical slow oscillations. Neuron 52: 871-882. CrossRef Medline

Katz LC, Shatz CJ (1996) Synaptic activity and the construction of cortical circuits. Science 274:1133-1138. CrossRef Medline

Khazipov R, Luhmann HJ (2006) Early patterns of electrical activity in the developing cerebral cortex of humans and rodents. Trends Neurosci 29: 414-418. CrossRef Medline

Khazipov R, Esclapez M, Caillard O, Bernard C, Khalilov I, Tyzio R, Hirsch J, Dzhala V, Berger B, Ben-Ari Y (2001) Early development of neuronal activity in the primate hippocampus in utero. J Neurosci 21:9770-9781. Medline

Khazipov R, Sirota A, Leinekugel X, Holmes GL, Ben-Ari Y, Buzsáki G (2004) Early motor activity drives spindle bursts in the developing somatosensory cortex. Nature 432:758-761. CrossRef Medline

Kim U, Bal T, McCormick DA (1995) Spindle waves are propagating synchronized oscillations in the ferret LGNd in vitro. J Neurophysiol 74: 1301-1323. Medline

Kleinfeld D, Delaney KR, Fee MS, Flores JA, Tank DW, Gelperin A (1994) Dynamics of propagating waves in the olfactory network of a terrestrial mollusk: an electrical and optical study. J Neurophysiol 72:1402-1419. Medline

Le Van Quyen M, Khalilov I, Ben-Ari Y (2006) The dark side of highfrequency oscillations in the developing brain. Trends Neurosci 29:419427. CrossRef Medline

Lischalk JW, Easton CR, Moody WJ (2009) Bilaterally propagating waves of spontaneous activity arising from discrete pacemakers in the neonatal mouse cerebral cortex. Dev Neurobiol 69:407-414. CrossRef Medline

Lubenov EV, Siapas AG (2008) Decoupling through synchrony in neuronal circuits with propagation delays. Neuron 58:118-131. CrossRef Medline

Lubenov EV, Siapas AG (2009) Hippocampal theta oscillations are travelling waves. Nature 459:534-539. CrossRef Medline

Luczak A, Barth ó P, Marguet SL, Buzsáki G, Harris KD (2007) Sequential structure of neocortical spontaneous activity in vivo. Proc Natl Acad Sci U S A 104:347-352. CrossRef Medline

Luhmann HJ, Prince DA (1991) Postnatal maturation of the GABAergic system in rat neocortex. J Neurophysiol 65:247-263. Medline
Massimini M, Huber R, Ferrarelli F, Hill S, Tononi G (2004) The sleep slow oscillation as a traveling wave. J Neurosci 24:6862-6870. CrossRef Medline

Math F, Davrainville JL (1979) Postnatal variations of extracellular free calcium levels in the rat. Influence of undernutrition. Experientia 35:13551356. CrossRef Medline

McCabe AK, Chisholm SL, Picken-Bahrey HL, Moody WJ (2006) The selfregulating nature of spontaneous synchronized activity in developing mouse cortical neurones. J Physiol 577:155-167. CrossRef Medline

Minamisawa G, Takahashi N, Matsuki N, Ikegaya Y (2009) Laterality of neocortical slow-wave oscillations in anesthetized mice. Neurosci Res 64: 240-242. CrossRef Medline

Minlebaev M, Ben-Ari Y, Khazipov R (2009) NMDA receptors pattern early activity in the developing barrel cortex in vivo. Cereb Cortex 19:688-696. CrossRef Medline

Minlebaev M, Colonnese M, Tsintsadze T, Sirota A, Khazipov R (2011) Early gamma oscillations synchronize developing thalamus and cortex. Science 334:226-229. CrossRef Medline

Momose-Sato Y, Nakamori T, Sato K (2012) Spontaneous depolarization wave in the mouse embryo: origin and large-scale propagation over the CNS identified with voltage-sensitive dye imaging. Eur J Neurosci 35: 1230-1241. CrossRef Medline

Moody WJ, Bosma MM (2005) Ion channel development, spontaneous activity, and activity-dependent development in nerve and muscle cells. Physiol Rev 85:883-941. CrossRef Medline

Mueller AL, Taube JS, Schwartzkroin PA (1984) Development of hyperpolarizing inhibitory postsynaptic potentials and hyperpolarizing response to $\gamma$-aminobutyric acid in rabbit hippocampus studied in vitro. J Neurosci 4:860-867. Medline

Obata K, Oide M, Tanaka H (1978) Excitatory and inhibitory actions of GABA and glycine on embryonic chick spinal neurons in culture. Brain Res 144:179-184. CrossRef Medline

O'Donovan MJ (1999) The origin of spontaneous activity in developing networks of the vertebrate nervous system. Curr Opin Neurobiol 9:94104. CrossRef Medline

Owens DF, Boyce LH, Davis MB, Kriegstein AR (1996) Excitatory GABA responses in embryonic and neonatal cortical slices demonstrated by gramicidin perforated-patch recordings and calcium imaging. J Neurosci 16:6414-6423. Medline

Paxinos G, Watson CR (1998) The rat brain in stereotaxic coordinates, Ed 4. New York: Academic.

Peinado A (2000) Traveling slow waves of neural activity: a novel form of network activity in developing neocortex. J Neurosci 20:RC54. Medline

Reboreda A, Raouf R, Alonso A, Séguéla P (2007) Development of cholinergic modulation and graded persistent activity in layer $\mathrm{v}$ of medial entorhinal cortex. J Neurophysiol 97:3937-3947. CrossRef Medline

Rheims S, Holmgren CD, Chazal G, Mulder J, Harkany T, Zilberter T, Zilberter Y (2009) GABA action in immature neocortical neurons directly depends on the availability of ketone bodies. J Neurochem 110:1330 1338. CrossRef Medline

Rochefort NL, Garaschuk O, Milos RI, Narushima M, Marandi N, Pichler B, Kovalchuk Y, Konnerth A (2009) Sparsification of neuronal activity in the visual cortex at eye-opening. Proc Natl Acad Sci U S A 106:15049_ 15054. CrossRef Medline

Roland PE, Hanazawa A, Undeman C, Eriksson D, Tompa T, Nakamura H, Valentiniene S, Ahmed B (2006) Cortical feedback depolarization waves: a mechanism of top-down influence on early visual areas. Proc Natl Acad Sci U S A 103:12586-12591. CrossRef Medline

Rubino D, Robbins KA, Hatsopoulos NG (2006) Propagating waves mediate information transfer in the motor cortex. Nat Neurosci 9:1549-1557. CrossRef Medline

Sanchez-Vives MV, McCormick DA (2000) Cellular and network mechanisms of rhythmic recurrent activity in neocortex. Nat Neurosci 3:10271034. CrossRef Medline

Sasaki T, Matsuki N, Ikegaya Y (2007) Metastability of active CA3 networks. J Neurosci 27:517-528. CrossRef Medline

Sasaki T, Matsuki N, Ikegaya Y (2011) Action-potential modulation during axonal conduction. Science 331:599-601. CrossRef Medline

Seki M, Kobayashi C, Takahashi N, Matsuki N, Ikegaya Y (2012) Synchronized spike waves in immature dentate gyrus networks. Eur J Neurosci 35:673-681. CrossRef Medline

Sheroziya MG, von Bohlen Und Halbach O, Unsicker K, Egorov AV (2009) 
Spontaneous bursting activity in the developing entorhinal cortex. J Neurosci 29:12131-12144. CrossRef Medline

Spitzer NC (2006) Electrical activity in early neuronal development. Nature 444:707-712. CrossRef Medline

Squire LR, Zola-Morgan S (1988) Memory: brain systems and behavior. Trends Neurosci 11:170-175. CrossRef Medline

Sun JJ, Luhmann HJ (2007) Spatio-temporal dynamics of oscillatory network activity in the neonatal mouse cerebral cortex. Eur J Neurosci 26: 1995-2004. CrossRef Medline

Tahvildari B, Fransén E, Alonso AA, Hasselmo ME (2007) Switching between "On" and "Off" states of persistent activity in lateral entorhinal layer III neurons. Hippocampus 17:257-263. CrossRef Medline

Takahashi N, Sasaki T, Matsumoto W, Matsuki N, Ikegaya Y (2010) Circuit topology for synchronizing neurons in spontaneously active networks. Proc Natl Acad Sci U S A 107:10244-10249. CrossRef Medline

Takahashi K, Saleh M, Penn RD, Hatsopoulos NG (2011a) Propagating waves in human motor cortex. Front Hum Neurosci 5:40. Medline

Takahashi N, Oba S, Yukinawa N, Ujita S, Mizunuma M, Matsuki N, Ishii S, Ikegaya Y (2011b) High-speed multineuron calcium imaging using Nipkow-type confocal microscopy. Curr Protoc Neurosci [Chapter 2] Unit 2:14. Medline

Takahashi N, Kitamura K, Matsuo N, Mayford M, Kano M, Matsuki N, Ikegaya Y (2012) Locally synchronized synaptic inputs. Science 335: 353-356. CrossRef Medline

Tazerart S, Vinay L, Brocard F (2008) The persistent sodium current gener- ates pacemaker activities in the central pattern generator for locomotion and regulates the locomotor rhythm. J Neurosci 28:8577-8589. CrossRef Medline

Watt AJ, Cuntz H, Mori M, Nusser Z, Sjöström PJ, Häusser M (2009) Traveling waves in developing cerebellar cortex mediated by asymmetrical Purkinje cell connectivity. Nat Neurosci 12:463-473. CrossRef Medline

Wu JY, Xiaoying H, Chuan Z (2008) Propagating waves of activity in the neocortex: what they are, what they do. Neuroscientist 14:487-502. Medline

Xu W, Huang X, Takagaki K, Wu JY (2007) Compression and reflection of visually evoked cortical waves. Neuron 55:119-129. CrossRef Medline

Yamada J, Okabe A, Toyoda H, Kilb W, Luhmann HJ, Fukuda A (2004) Cluptake promoting depolarizing GABA actions in immature rat neocortical neurones is mediated by NKCC1. J Physiol 557:829-841. CrossRef Medline

Yang JW, Hanganu-Opatz IL, Sun JJ, Luhmann HJ (2009) Three patterns of oscillatory activity differentially synchronize developing neocortical networks in vivo. J Neurosci 29:9011-9025. CrossRef Medline

Yoshida M, Alonso A (2007) Cell-type-specific modulation of intrinsic firing properties and subthreshold membrane oscillations by the $\mathrm{M}(\mathrm{Kv} 7)$ current in neurons of the entorhinal cortex. J Neurophysiol 98:27792794. CrossRef Medline

Zhang LI, Poo MM (2001) Electrical activity and development of neural circuits. Nat Neurosci 4:1207-1214. CrossRef Medline 